\title{
Spatio-temporal Variation of Benthic Metabolism in a Large Regulated River
}

Craig Irwin, The University of Western Ontario

Supervisor: Yates, Adam G., The University of Western Ontario

A thesis submitted in partial fulfillment of the requirements for the Master of Science degree in Geography

(C) Craig Irwin 2017

Follow this and additional works at: https://ir.lib.uwo.ca/etd

Part of the Environmental Indicators and Impact Assessment Commons

\section{Recommended Citation}

Irwin, Craig, "Spatio-temporal Variation of Benthic Metabolism in a Large Regulated River" (2017).

Electronic Thesis and Dissertation Repository. 5004.

https://ir.lib.uwo.ca/etd/5004

This Dissertation/Thesis is brought to you for free and open access by Scholarship@Western. It has been accepted for inclusion in Electronic Thesis and Dissertation Repository by an authorized administrator of Scholarship@Western. For more information, please contact wlswadmin@uwo.ca. 


\begin{abstract}
Spatio-temporal patterns of benthic metabolism were measured to determine associations with substrate (cobble vs sand), channel location (main vs side channel), flow regulation (medium-head vs low-head) and temporal variability during the summer months. Benthic metabolism was estimated in two reaches of the Saint John River in New Brunswick, Canada using benthic chambers. General linear models indicated gross primary production (GPP) and community respiration (CR) was greater in cobble substrate in June, but only GPP was greater in July. CR differed between channel locations in July with greater rates in the side channel. Assessment of flow regulation showed greater GPP in the medium-head reach during July and August, but greater CR in July only. Regression analysis indicated temporal variation in GPP was associated with light, whereas CR was associated with GPP and water temperature. Results demonstrate that there are strong spatial and temporal trends for benthic metabolism in a large river.
\end{abstract}

Keywords: Benthic metabolism, large river, Saint John River, spatio-temporal variation, gross primary production, community respiration 


\section{Table of Contents}

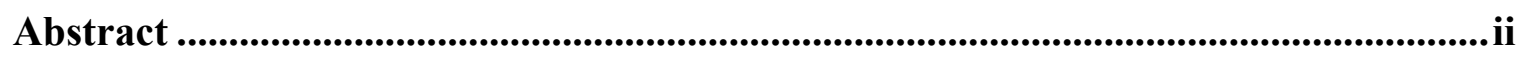

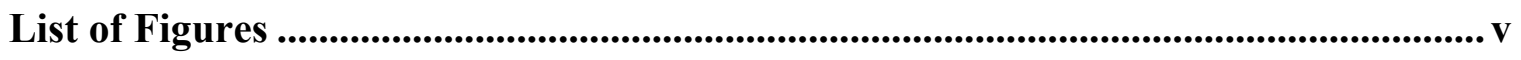

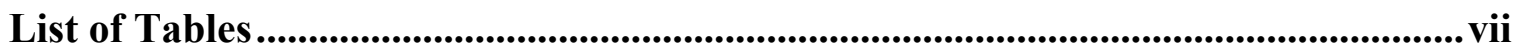

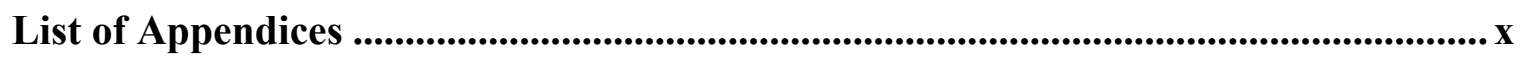

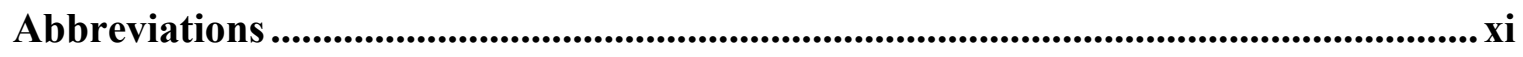

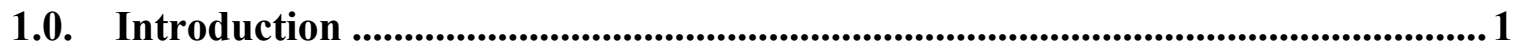

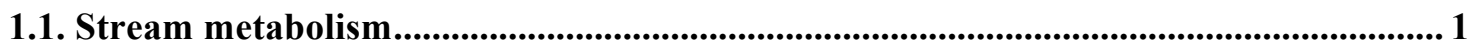

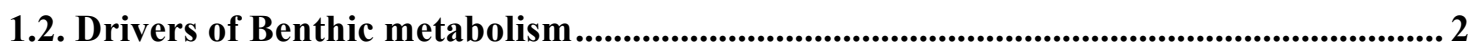

2.0. Research Goals and Hypothesis .................................................................6 6

2.1. Assessment 1: River Substrate .............................................................................................6 6

2.2. Assessment 2: Channel Location ................................................................................................... 6

2.3. Assessment 3: Flow Regulation Effects ..................................................................................... 7

2.4. Assessment 4: Temporal Variability ............................................................................

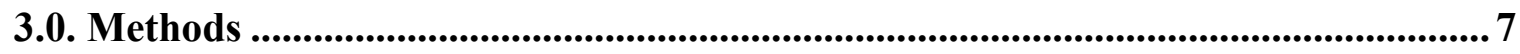

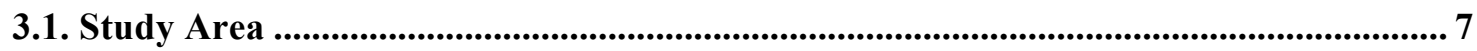

3.2. Study Design and Site Selection ............................................................................................... 10

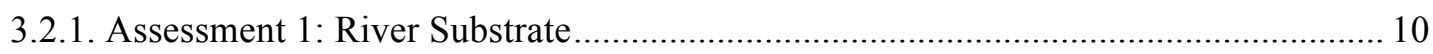

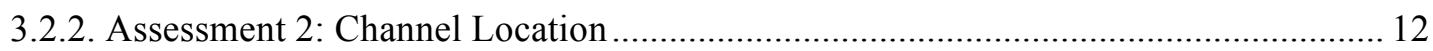

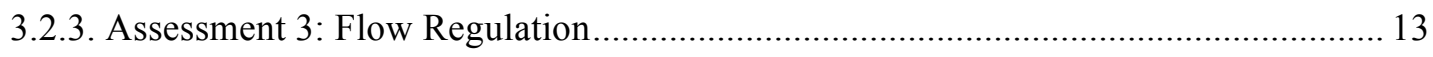

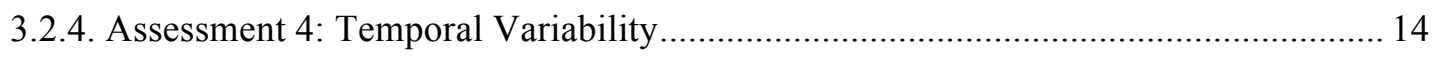

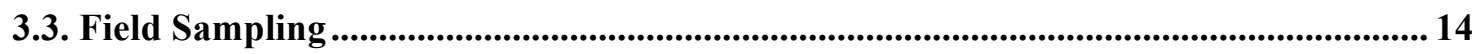

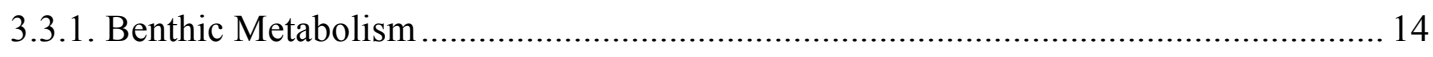

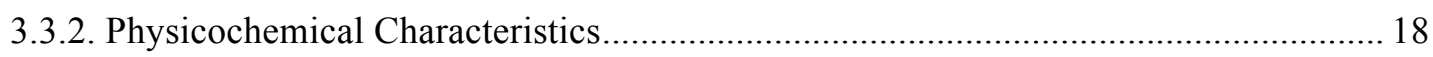

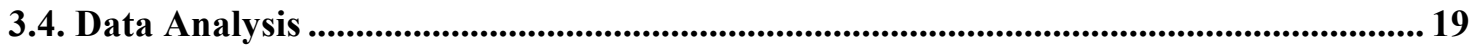

4.0. Results....................................................................................................................................... 21

4.1. Assessment 1: River Substrate ................................................................................................. 21

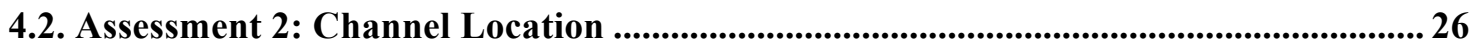




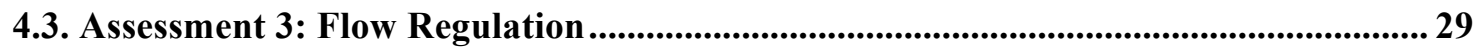

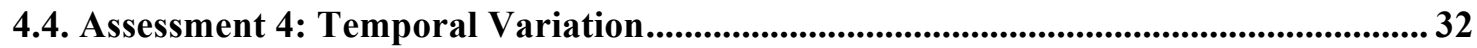

4.4.1. Hypothesis Testing of Drivers of Benthic Metabolism ............................................. 37

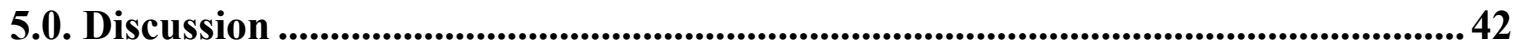

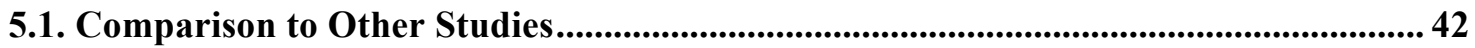

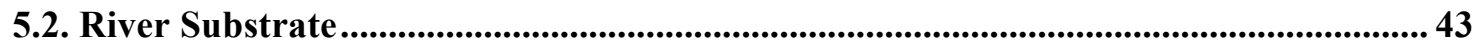

5.3. Channel Location .................................................................................................................... 45

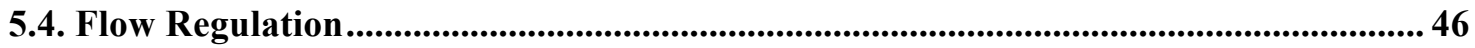

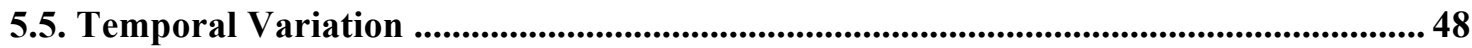

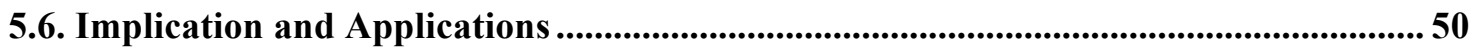

5.7. Study Limitations and Further Research .....................................................................51

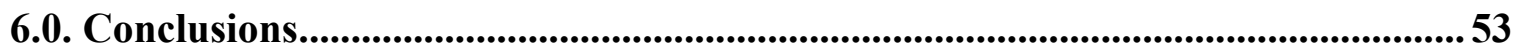

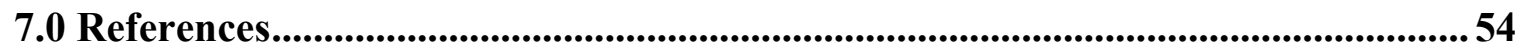

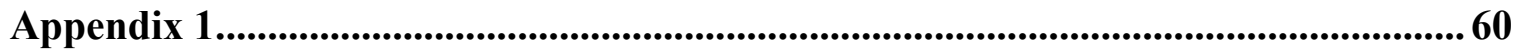

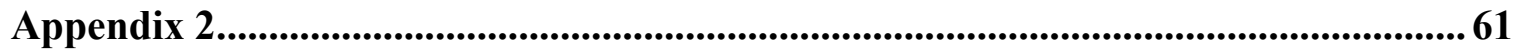

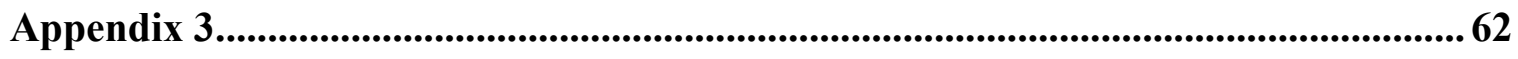

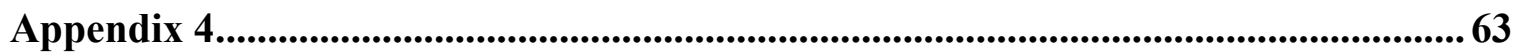

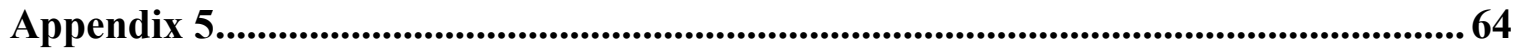

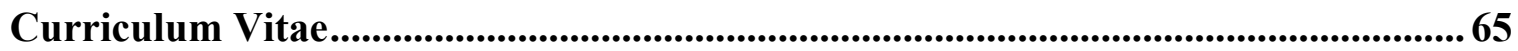




\section{List of Figures}

Figure 3.1.: Location of four sites in the Saint John River, New Brunswick for which benthic metabolism was estimated. Panel A indicates the location of study sites within the Saint John River, with the inset identifying the location of the study region in Canada. Panels B, C and D indicate site locations corresponding to field assessments 1, 2 and 3, respectively.

Figure 3.2.1a.: Downstream view of the cobble substrate site in the Saint John River (left) with a close up of an individual chamber (right).

Figure 3.2.1b.: Downstream view from the sand substrate site in the Saint John River (left) and a close up of the benthic chambers pushed into the stream bed (right).

Figure 3.2.2.: An upstream view from the side channel site in the Saint John River (left) and a benthic chamber set up with substrate enclosed (right).

Figure 3.2.3.: A downstream view towards Hartland in the upstream sampling site in the Saint John River (left) and a benthic chamber with large cobble substrate (right).

Figure 3.3.: (A) Typical organization of a closed-base benthic chamber system for cobble measurements. Once the cobble substrate is placed inside, the benthic chamber is sealed with a plastic base and duct tape. The outflow of the chamber is connected to a Whale inline centrifugal pump that pumps water through an YSI Sonde (model 6600 or EXO) and back into the chamber through the inflow, which is all connected in series. A dock float was used to hold batteries that powered the pump.

(B) An overhead view of the distribution of benthic chambers at each sampling site. Four chambers were placed around each dock and arranged to cover variability within each sampling patch. 
Figure 4.1.: Average gross primary productivity (GPP) (A), community respiration (CR) (B), and net daily metabolism (NDM) (C) ( \pm standard deviation) measured as benthic metabolism rates between coarse and fine substrate patches during the summer of 2016. Letters denote post-hoc analysis similarity and differences in cases where an interaction was present. The * represent differences from GLM.

Figure 4.2.: Average gross primary productivity (GPP) (A), community respiration (CR) (B), and net daily metabolism (NDM) (C) ( \pm standard deviation) measured as benthic metabolism rates between main and side channel patches during the summer of 2016. Letters denote post-hoc analysis similarity and differences in cases where an interaction was present. The * represents a significant difference between sites.

Figure 4.3.: Average gross primary productivity (GPP) (A), community respiration (CR) (B), and net daily metabolism (NDM) (C) ( ${ }^{\text {standard deviation }) ~ m e a s u r e d ~ a s ~ b e n t h i c ~ m e t a b o l i s m ~}$ rates coarse substrate patches in a medium-head and low-head reach. Letters denote post-hoc analysis similarity and differences when an interaction was present. The * represents a difference between sites from the GLM.

Figure 4.4.: Mean daily temperature $\left({ }^{\circ} \mathrm{C}\right)$ and mean bed PAR $\left(\mathrm{mol} \mathrm{m} \mathrm{m}^{-2} \mathrm{~d}^{-1}\right)$ from each sampling period throughout the summer of 2016.

Figure 4.5.: Nutrient concentrations from once a week sampling in the Saint John River in the 2016 study period.

Figure 4.6.: Dissolved organic carbon $(\mathrm{mg} / \mathrm{L})$, Chlorophyll-a $\left(\mu \mathrm{g} / \mathrm{cm}^{2}\right)$ and ash free dry mass $\left(\mathrm{mg} / \mathrm{cm}^{2}\right)$ for each sampling week during the summer of 2016. 


\section{List of Tables}

Table 4.1.: Summary of the physical variables measured daily during each field assessment. Mean, standard deviation and coefficient of variation were averaged over the course of the sampling week.

Table 4.2.: Water chemistry results collected weekly at each site during the sampling period. Chlorophyll-a and Ash Free Dry Mass (AFDM) measurements taken from substrate enclosed in the benthic chambers.

Table 4.3.: Results of hypothesis testing of the drivers of temporal variation in GPP. Factors in models include photosynthetically active radiation (PAR), water temperature (TEMP) and water depth (DEPTH).

Table 4.4.: Results of models used to test hypothesis behind drivers of CR. Models include gross primary production (GPP), water temperature (TEMP), and water depth (DEPTH).

Table 4.5.: Results from hypothesis testing of parameters influencing NDM. Models include photosynthetically active radiation (PAR), water temperature (TEMP), and water depth (DEPTH).

Table 5.1.: Measured rates of benthic metabolism in temperate North American rivers. Mean rates and standard deviation are shown. 


\section{List of Appendices}

Appendix 1. Location and characteristics of sites used in Assessments 1-4 in the Saint John River. All measurements were taken during the summer of 2016.

Appendix 2. Methods and detection limits of water quality parameters sampled in the Saint John River.

Appendix 3. A priori gross primary productivity models for temporal trends in benthic metabolism in the Saint John River, New Brunswick, Canada. Abbreviations used to describe the model structure are listed under each hypothesis with the exception of the ordinate intercept (I).

Appendix 4. A priori community respiration models for temporal trends in benthic metabolism in the Saint John River, New Brunswick, Canada. Abbreviations used to describe the model structure are listed under each hypothesis with the exception of the ordinate intercept (I).

Appendix 5. A priori net daily metabolism models for temporal trends in benthic metabolism in the Saint John River, New Brunswick, Canada. Abbreviations used to describe the model structure are listed under each hypothesis with the exception of the ordinate intercept (I). 


\section{Abbreviations}

GPP $=$ Gross Primary Productivity

$\mathrm{CR}=$ Community Respiration

PAR $=$ Photosynthetically Active Radiation

$\mathrm{NDM}=$ Net Daily Metabolism

$\mathrm{R}=$ Respiration Rate

DO $=$ Dissolved Oxygen Concentration

ANOVA $=$ Analysis of Variance

GLM $=$ General Linear Model

$\mathrm{AIC}=$ Akaike Information Criterion

TEMP $=$ Water Temperature

DEPTH $=$ Water Depth Change

$\mathrm{SD}=$ Standard Deviation

$\mathrm{CV}=$ Coefficient of Variation 


\subsection{Introduction}

Large rivers are dominant landscape features and have been focal points of human civilization for millennia. Indeed, humans are reliant on the many naturally occurring ecosystem services provided by ecological processes in large rivers, such as fisheries, drinking and irrigation waters, as well as nutrient cycling and water purification (MEA, 2005). Large rivers are also frequently dammed and managed to regulate flows for hydroelectric generation, flood control and water storage, changing the flow regime of the river and associated ecological functions (Young et al., 2004; O'Connor et al., 2012). However, quantitative research and knowledge of the processes driving ecological functions within large river systems are limited ( $\mathrm{Li}$ et al., 2015). In particular, key ecological processes, such as stream metabolism, have been understudied in large rivers (Cardinale et al., 2002; Tank et al., 2008).

\subsection{Stream metabolism}

Stream metabolism is the balance between the amount of carbon fixation and consumption derived from gross primary production (GPP) and community respiration (CR), respectively, with the difference between the two an indication of net daily metabolism (NDM) (Clapcott \& Barmuta, 2010). Measurements of primary production and respiration provide insight into an ecosystem's trophic structure and important ecological processes within a river, such as cycling of nutrients and organic matter (Mulholland et al., 2001; Bernot et al., 2010). Stream metabolism can be indicative of nutrient cycling because primary producers require inorganic nutrients (i.e., nitrogen and phosphorus) to grow, enabling nutrient uptake to be reflected in rates of GPP (Bernot et al., 2010). Likewise, CR indicates the amount of organic matter being broken down providing insight into organic matter processing within a system (Mulholland et al., 2001; Bernot et al., 2010). Thus, metabolism is indicative of whether the ecosystem food web is supported primarily by carbon fixation within the stream (autochthonous) or from 
external carbon sources (allochthonous) (Rosenfeld \& Roff, 1991; Muholland et al., 2001). Because the majority of organisms in rivers reside in the benthic zone, benthic metabolism measurements provide crucial information for understanding stream metabolism in lotic systems (Bunn et al., 1999; Fellows et al., 2006).

\subsection{Drivers of Benthic metabolism}

Benthic metabolism is controlled, in part, by a river's physico-chemical characteristics. For example, studies of small streams have found that GPP and CR are strongly linked to local environmental conditions, including photosynthetically active radiation (PAR) (Fellows et al., 2006), temperature (Clapcott \& Barmuta, 2010; Velasco et al., 2003), organic matter (Bernot et al., 2010), nutrient availability (Kendrick \& Huryn, 2015), flow regime (Chester \& Norris, 2006; Cardinale et al., 2002; Acuna et al., 2011) and substrate type (Clapcott \& Barmuta, 2010). GPP is primarily controlled by light and nutrients as these parameters limit the amount of algal biomass in a river (Mulholland et al., 2001; Bernot et al., 2010), whereas CR has been strongly correlated with increasing temperature, and organic matter (Bernot et al., 2010). In addition, benthic metabolism is influenced by physical habitat characteristics. For example, impacts of flow vary depending on substrate type, with more stable substrates, such as cobbles, having been shown to have greater rates of GPP than finer substrates, such as sand, that are more likely to be mobilized and scour primary producers, during high velocity flows (Young et al., 2004; Acuna et al., 2011; O’Connor et al., 2012). The understanding of spatial and temporal patterns of stream metabolism and associated drivers have primarily been derived from small, pristine streams and have not been well investigated in large rivers (Tank et al., 2008; Izagirre et al., 2008; Acuna et al., 2011).

Studies applying knowledge of drivers of metabolism, such as PAR, temperature and discharge, derived from small streams in large rivers have had some contrasting results. For instance, a study by Naiman (1983) in the Moisie River found PAR was not significantly associated with metabolism, whereas in their study of the Mississippi River, Dodds et al. (2013) observed PAR to have a positive but indirect overall effect on GPP. 
The relationship between PAR and GPP was likely caused by seasonality, but is an example of the complex relationships among environmental variables when trying to distinguish individual drivers of metabolism (Dodds et al., 2013). However, multiple studies have indicated a strong positive association between water temperature and metabolism rates in large rivers, where both primary production (Dodds et al., 2013) and respiration (Dodds et al., 2013; Aritsi et al., 2014) increased with rising temperature. Discharge was also found to be positively associated with GPP and CR in three tributaries of the Ebro River (Aritsi et al., 2014) as well as being associated with CR in the Mississippi River (Dodds et al., 2013). Disentangling potential drivers behind GPP and $\mathrm{CR}$ is important for understanding the abiotic controls behind the dominant energy source in a river (autotrophic or heterotrophic). In general, the trophic status of large rivers has varied between studies, as some systems have been reported as autotrophic (Naiman, 1983), and others heterotrophic (Minshall et al., 1992; Dodds et al., 2013, Aritsi et al., 2014). Although reported trophic status of rivers varies, the limited knowledge we have about metabolism patterns in large rivers has been constrained to a similar substrate type as a majority of studies (see Naiman \& Sedall, 1980; Naiman, 1983; Minshall et al., 1992; Aristi et al., 2014) have all focused on cobble substrate. To enhance our understanding of metabolism in large rivers the breadth of substrate types studied needs to be expanded.

River substrate is influenced by the geology of the surrounding catchment environment with a river containing a mosaic of substrate, ranging from areas containing a wide spectrum of sizes to defined patches of a single dominant particle size. A study by Cardinale et al. (2002) found homogenous substrate patches, such as, sand substrate, have lower GPP and CR than patches of higher heterogeneity, although the mechanisms behind these results have only been speculated. Another small stream study by Rier \& King (1996) found net daily metabolism (NDM) within cobble sites was autotrophic, whereas sand sites produced heterotrophic conditions, suggesting patches consisting of homogeneous substrate have consistent rates of metabolism. However, studies of how physical habitat heterogeneity affects ecological processes in large rivers, like stream metabolism, are limited (Cardinale et al., 2002). 
The majority of research on large rivers has viewed these habitats as stable, single channel systems (Ward et al., 2001). However, there has been an epistemological shift and large rivers are increasingly recognized as a mosaic of unique habitat types with biological processes that are not restricted to the main active channel. Additional habitats within large rivers can include areas with restricted flow connectivity creating floodplains, backwaters and side channel areas, each with their own physical and biological characteristics. For example, hydrological connectivity between main channel and off-channel habitat in a river can influence environmental conditions linked to GPP and $\mathrm{CR}$, such as nutrient availability, organic matter, turbidity and flow disturbance (Ward, 1999; Sobotka \& Phelps, 2016). In addition, Preiner et al., (2008) found connectivity between main and off-channel habitat in the River Danube, Austria, to be important for benthic metabolism as rates were greatest at low hydrological connectivity. Investigating potential differences of benthic metabolism between main and off-channel habitat is an important step to improving our understanding of large rivers given the ecological importance of these off channel areas.

Large rivers are frequently subjected to flow regulation and can be managed for both power usage and reservoir capacity throughout the year (Brismar, 2002; Young et al., 2004; O'Connor et al., 2012). Indeed, 59\% of the world's large river systems are affected by dams leading to altered channel morphology, sediment transport, water chemistry, and flow regimes (Ward \& Stanford, 1983; Ligon et al., 1995; Karr \& Chu 2000; Munn \& Brusven, 2004; Nilsson et al, 2005; Graf, 2006; Aristi et al., 2014). Regulation has homogenized flow regimes in rivers by altering the degree and timing of high and low flow events within rivers (Poff et al., 2007), whereas unregulated river reaches have been shown to have greater discharge, more frequent flood events and greater maximum flows (Graf, 2006). Moreover, stream metabolism in unregulated river reaches responds to high flows causing GPP and CR to decrease (Young et al., 2004; O'Connor et al., 2012) and should therefore differ from a regulated reach, where a more stable environment results in an increase in the establishment of primary producers (Ward \& Stanford, 1983; Ligon et al., 1995; Aritsi et al., 2014). With the majority of large rivers 
being regulated, it is essential to increase our knowledge of the effects of flow regulation on river metabolism.

Seasonality influences stream metabolism through variations in PAR, temperature and flow because these abiotic controls vary temporally (Roberts et al., 2007). For example, because of the open canopy in wider rivers, light regime can be quite variable on a daily basis due to cloud cover, whereas smaller streams experience seasonal light limitation due to leaf emergence in the tree canopy (Naiman \& Sedall, 1980). In colder seasons, lower water temperatures lead to reduced heterotrophic activity resulting in lower CR compared to warmer seasons (Izagirre et al., 2008). However, in the study of a small, shaded stream, Izagirre et al. (2008) found that GPP hit a peak in cooler spring months whereas open reaches peaked during the warm summer months; likely a result of variations in PAR. During the summer months in temperate ecosystems, daylight hours are longest increasing light intensity, water temperature and biomass (Acuna et al., 2011). Quantifying patterns of temporal variability is important to understanding drivers of metabolism because most measurements are made during ideal conditions (e.g. sunny days) making general interpretation of results difficult. Seasonal effects may also be mitigated by river regulation, as summer temperatures could potentially be kept colder and spring temperatures made warmer depending on the type of dam (Preece \& Jones, 2002). Studies of seasonal effects on stream metabolism are few and have been of limited scope in large regulated river reaches (but see Dodds et al., 2013; Aritsi et al., 2014).

Our current understanding of spatial and temporal drivers of variation in benthic metabolism has been largely derived from studies of small, headwater streams (Bunn et al., 1999; Fellows et al., 2006; Tank et al., 2008; Izagirre et al., 2008). In contrast, there have been comparably few studies of the controls of spatial and temporal patterns of benthic metabolism in large rivers (but see Munn and Brusven, 2003; Dodds et al., 2013; Aritsi et al., 2014). As a result, there is an immediate need to assess if our knowledge of spatio-temporal patterns of stream metabolism in small streams can be scaled to large rivers. The goal of this study was thus to describe patterns of spatial and temporal variation of benthic metabolism in a large, regulated river. 


\subsection{Research Goals and Hypothesis}

This thesis describes patterns of spatial and temporal variation of benthic metabolism in a large regulated river. This goal was achieved by conducting four field assessments that measured mean rates of benthic metabolism and the associated effects of river substrate, channel location, flow regulation and temporal variation.

\subsection{Assessment 1: River Substrate}

Objective: Compare rates of benthic metabolism between patches of coarse and fine substrate located within a regulated river reach among the summer months (June, July and August).

Hypothesis: During the June sampling period, metabolism rates will not be significantly different between coarse (cobble) and fine (sand) sediment types because of low algal and microbial biomass. However, there will be a significant difference in benthic metabolism between substrate types during July and August, because coarse substrates are more stable allowing algae and microbes to establish greater biomass than on fine substrates.

\subsection{Assessment 2: Channel Location}

Objective: Compare benthic metabolism between two channel locations (i.e., main and side channel) between summer months (i.e. July, August).

Hypothesis: There will be a significant difference in rates of metabolism between habitat types during July and August because biomass accumulation will be increasing within each channel, but at different rates over the summer. In comparison to the side channel, the main channel will have lower rates of GPP and CR because of higher riverbed scouring during spring freshet and storm events will delay and reduces algal biomass accumulation over the summer period. 


\subsection{Assessment 3: Flow Regulation Effects}

Objective: Compare rates of benthic metabolism between two regulated (i.e., low-head and medium-head) river reaches among summer months (June, July and August).

Hypothesis: There will be a significant difference in the rate of benthic metabolism between coarse substrates in the low-head and medium-head regulated reaches. Benthic metabolism will be significantly greater in the medium-head reach during July and August because of reduced riverbed disturbance resulting from greater flow regulation, reducing scouring and allowing algae to establish greater biomass on substrate. However, benthic metabolism will not be significantly different between low and medium-head reaches at the beginning of summer (June) because of high flow disturbances and associated streambed scouring in both reaches from increased runoff after the winter season.

\subsection{Assessment 4: Temporal Variability}

Objective: Assess temporal variation in rates of benthic metabolism throughout the summer in a regulated river reach.

Hypothesis: Rates of benthic metabolism will be greatest in mid-July because water temperature and bed PAR will peak during this time period allowing maximum algal biomass accrual. Rates of GPP and CR will increase from June until mid-July and then will continuously decrease as summer concludes.

\subsection{Methods}

\subsection{Study Area}

This study was conducted in the Saint John River, near Fredericton, New Brunswick, Canada. The Saint John River flows south through New Brunswick to the city of Saint John where it discharges into the Bay of Fundy (Figure 1A). The river basin has an area of about $55,000 \mathrm{~km}^{2}$, and the river is the largest river in New Brunswick in both discharge $\left(1100 \mathrm{~m}^{3} / \mathrm{s}\right)$ and length $(\sim 700 \mathrm{~km})$ (Cunjak \& Newbury, 2005). The large 
volume of water allows the generation of hydroelectric power at the 660 MW Mactaquac Generating Station upstream of Fredericton, which is classified as a medium-head dam as it is taller than $30 \mathrm{~m}$ (sensu Majumder \& Gosh 2013).

This study focused on two river reaches located up and downstream of the dam (Figure 3.1A). The downstream reach extended from medium-head Mactaquac Generating Station to Fredericton and was used for Assessments 1 (Figure 3.1B), 2 (Figure 3.1C) and 4 (Figure 3.1B \& C) of the research. This reach is characterized by a wide $(750 \mathrm{~m})$ channel with islands of alluvial deposits of gravel and sand bars dispersed along this stretch (Curry \& Munkittrick, 2005). Substrate in the downstream reach is a mosaic of either patches of cobble or sand. Land use in the downstream reach is a mixture of forest, urban development and agriculture. In contrast, the upstream reach near Hartland, New Brunswick is affected by the low-head $(<30 \mathrm{~m}$ tall) Beechwood Dam and contains a few islands with a riverbed that is dominated by cobble sized substrate (Figure 3.1D). Land use along the upstream reach is primary agricultural (Kidd et al., 2011). Water chemistry conditions are circumneutral ( $\mathrm{pH} 7.3$ to 8.0 ) and specific conductivity ranged from 92.4 to $147.8 \mu \mathrm{S} / \mathrm{cm}$ within the study reaches. 

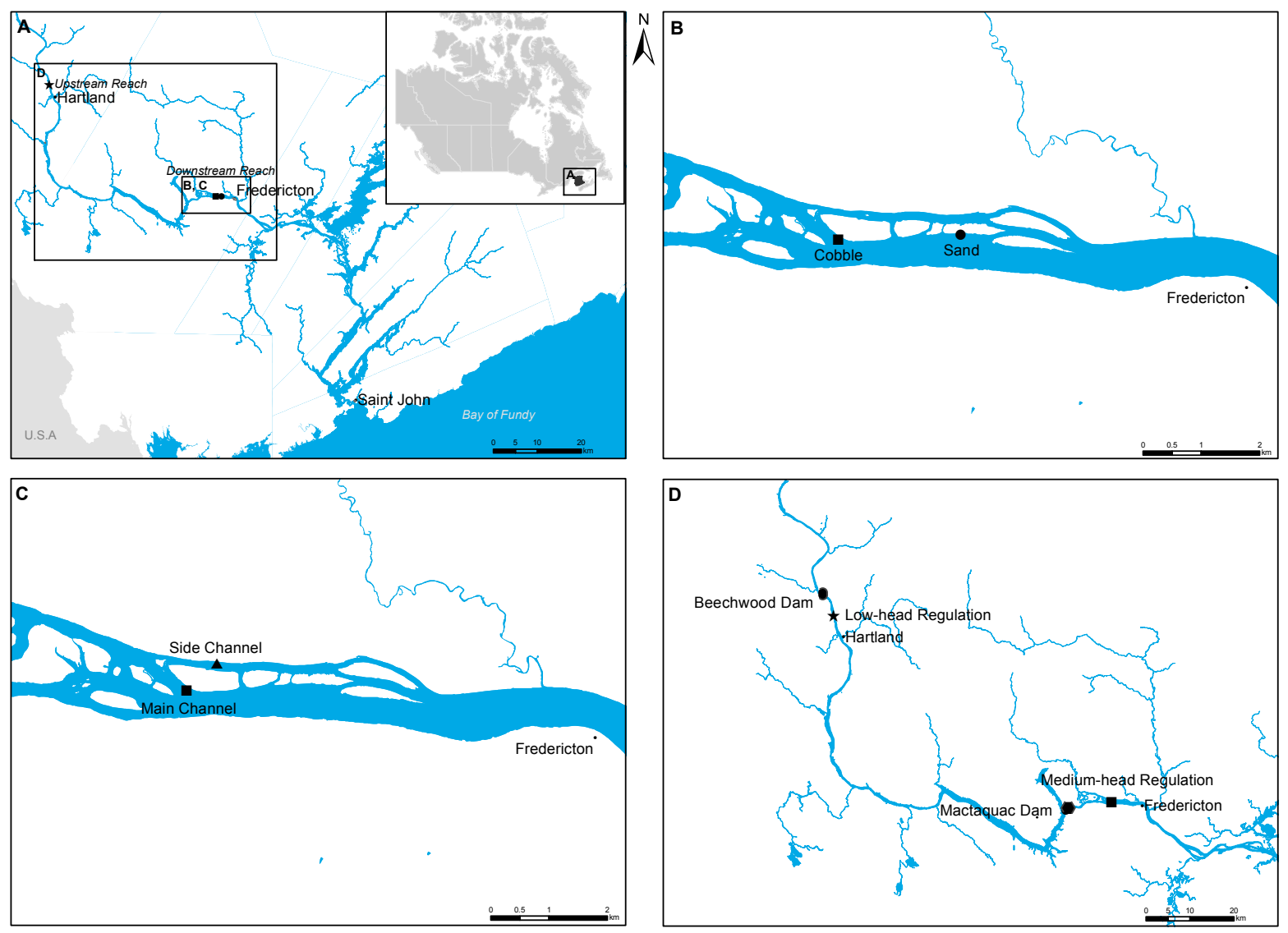

Figure 3.1. Location of four sites in the Saint John River, New Brunswick for which benthic metabolism was estimated. Panel A indicates the location of study sites within the Saint John River, with the inset identifying the location of the study region in Canada. Panels B, C and D indicate site locations corresponding to field assessments 1, 2 and 3, 


\subsection{Study Design and Site Selection}

\subsubsection{Assessment 1: River Substrate}

The effect of substrate size on benthic metabolism in a large river was assessed by comparing two patches (hereafter sites) of substrate within the main channel portion of the downstream reach of the Saint John River. The selected sites differed in substrate size (i.e., cobble (Figure 3.2.1A) vs sand (Figure 3.2.1B) substrate) but were similar in patch size area, water velocity, light availability and depth (see Appendix 1 for site characteristics). Benthic metabolism was sampled at eight locations at each site to capture within site variability in substrate. To assess the possible effects of substrate type with seasonal variation on benthic metabolism, measurements were undertaken during three different periods between June 6 and August 12. Benthic metabolism was measured daily over a four-day period for two of three sampling events, but only for a three-day period from July 4-7 due to severe weather. 

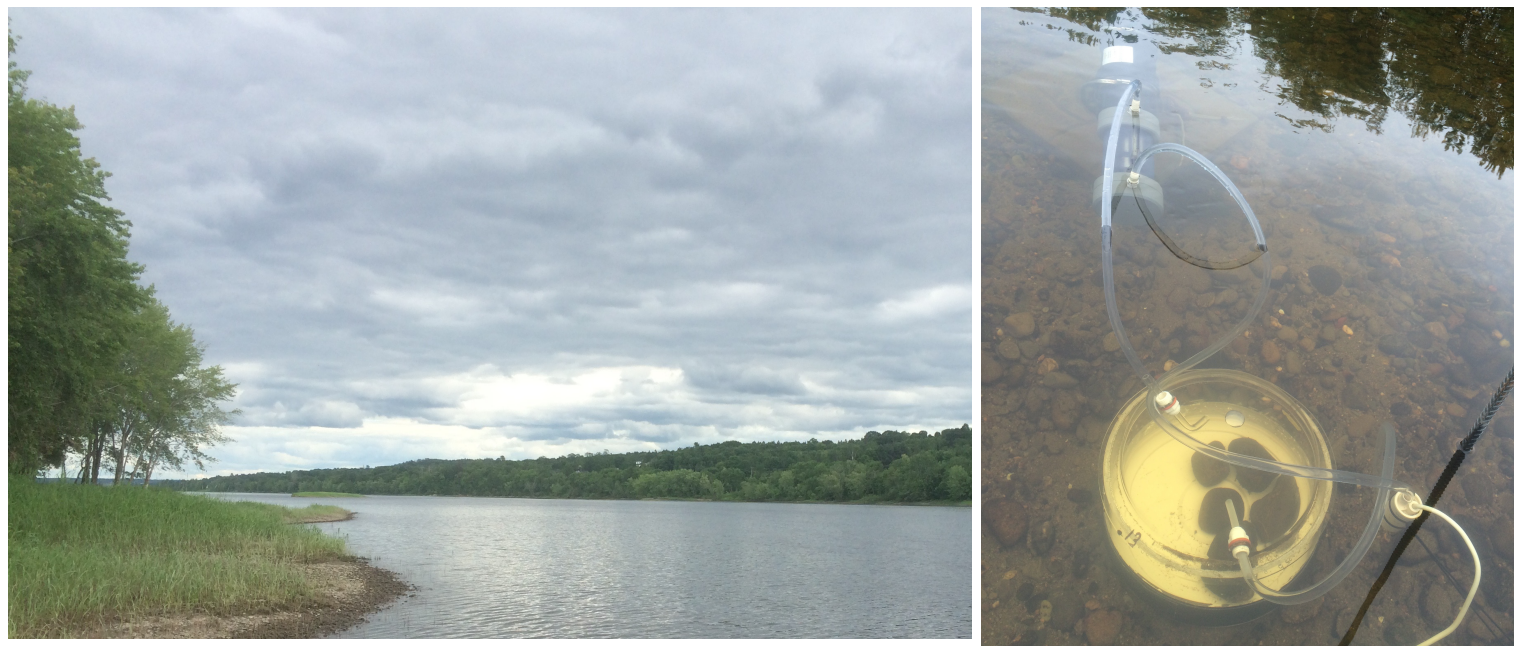

Figure 3.2.1A. Downstream view of the cobble substrate site in the Saint John River (left) with a close up of an individual chamber (right).
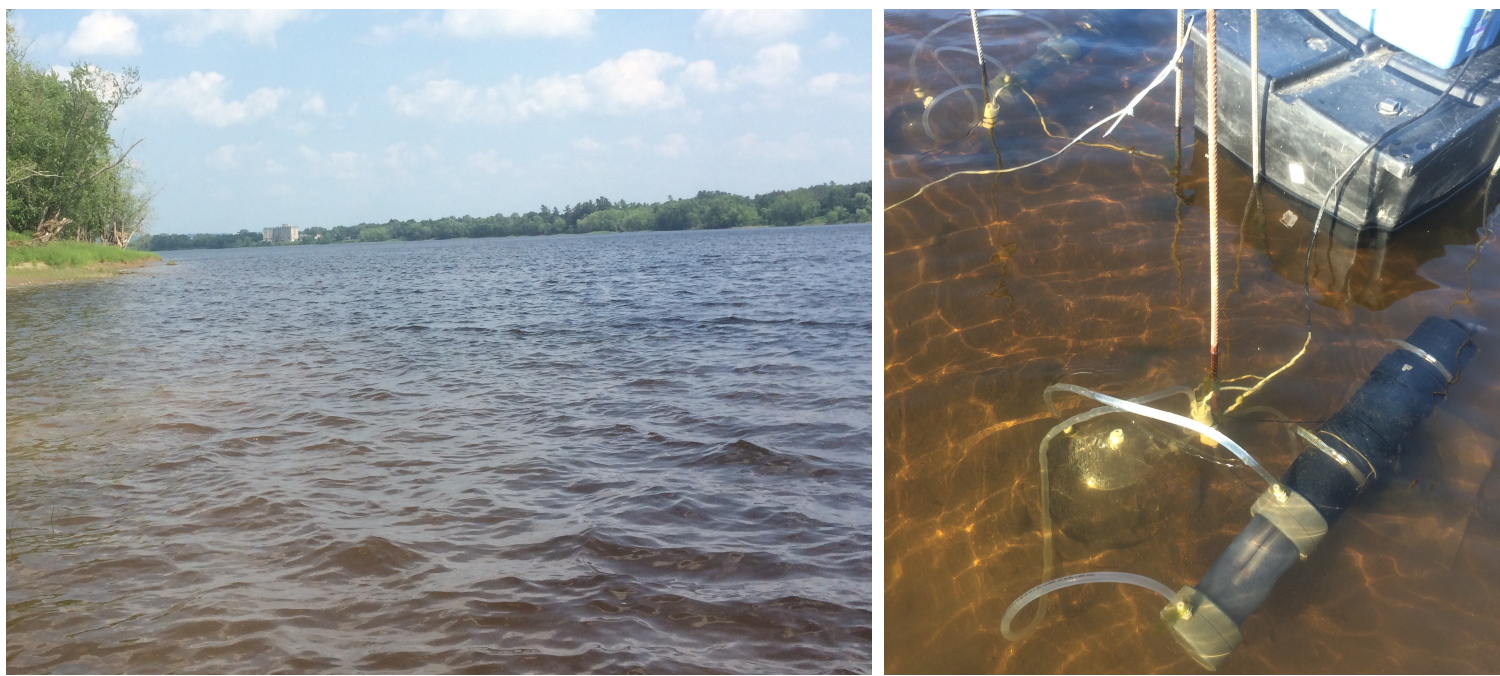

Figure 3.2.1B. Downstream view from the sand substrate site in the Saint John River (left) and a close up of the benthic chambers pushed into the stream bed (right). 


\subsubsection{Assessment 2: Channel Location}

The effect of channel location on benthic metabolism was determined by comparing two sites within the downstream reach of the Saint John River. One site was the coarse substrate main channel site used in Assessment 1 (see Figure 3.1C \& Figure 3.2.1A) and the other site was located in a side channel area (Figure 3.1C). The side channel site (Figure 3.2.2) was selected to be comparable to the main channel site in substrate and patch size, water velocity, light availability and depth. Benthic metabolism was measured at eight locations within each site. Sampling locations were selected to encompass the variability in substrate characteristics within each site. Evaluation of seasonality effects on metabolism was assessed during two different periods between July 11 and August 18. Metabolism measurements for the July sampling took place over a four-day period, and measurements in August took place over a three-day period.
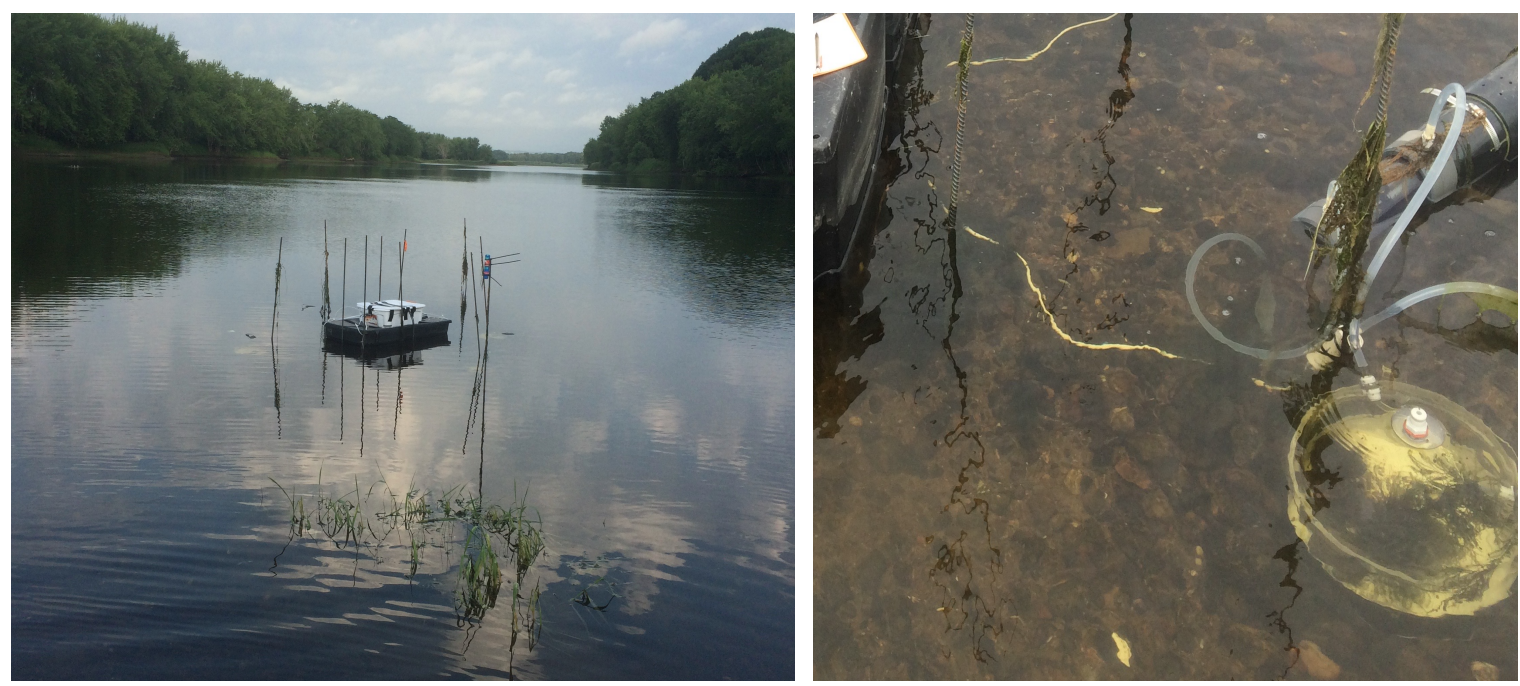

Figure 3.2.2. An upstream view from the side channel site in the Saint John River (left) and a benthic chamber set up with substrate enclosed (right). 


\subsubsection{Assessment 3: Flow Regulation}

Effects of river regulation on benthic metabolism was determined by comparing rates of metabolism measured at a site located at the low-head regulated, upstream reach (Figure 3.2.3) with measurements from the medium-head regulated downstream reach (Figure 3.2.1a) of the Saint John River. Sites consisted of a single coarse substrate patch in each reach (Figure 3.1D). Sites were representative of the overall physical conditions of the reach and comparable in terms of habitat patch size, water velocity, light availability and depth. Benthic metabolism was examined at eight locations within each patch. Sampling locations were arranged to account for the variability in substrate characteristics within each patch. To assess effects of seasonality, benthic metabolism was evaluated during three different periods between June 21 and August 26. June and July benthic metabolism samplings took place daily over a four-day period, whereas August sampling lasted 48-hours because of inclement weather.
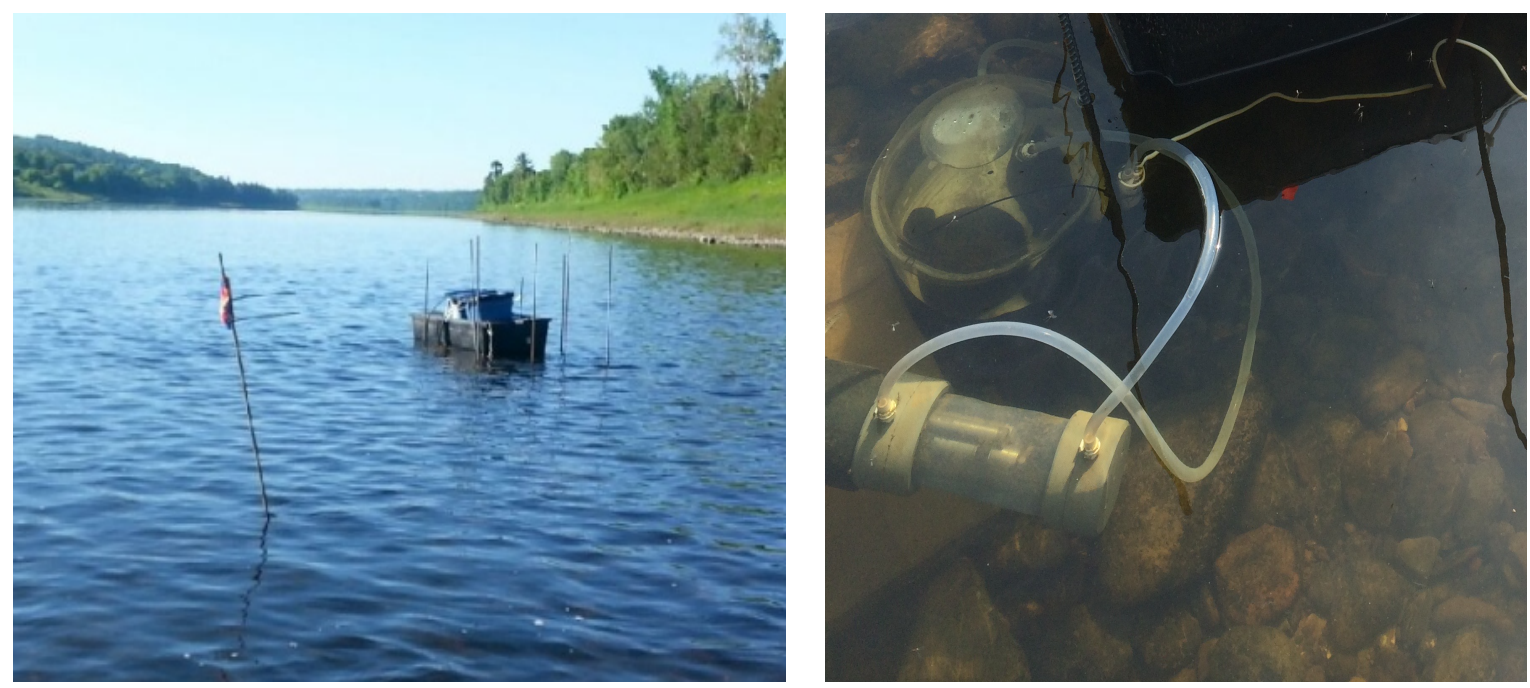

Figure 3.2.3. A downstream view towards Hartland in the upstream sampling site in the Saint John River (left) and a benthic chamber with large cobble substrate (right). 


\subsubsection{Assessment 4: Temporal Variability}

Temporal variation in benthic metabolism was assessed by comparing rates of metabolism at the medium-head regulated main channel cobble site (Fig. 3.2.1a) used in assessments 1, 2 and 3 over eight weeks of the summer of 2016. Benthic metabolism was measured at eight locations within the patch each sampling period. Sampling locations were arranged to capture the variability in substrate characteristics within the patch. To assess seasonality, benthic metabolism was measured between June 6 and August 26.

\subsection{Field Sampling}

\subsubsection{Benthic Metabolism}

Benthic metabolism parameters (i.e., GPP, CR and NDM) were estimated using benthic chambers and the dissolved oxygen method (Grace \& Imberger, 2006). Sealed chambers were used to isolate a known area of riverbed to measure changes in dissolved oxygen concentrations. Each chamber consisted of a Whale inline centrifugal pump connected to an acrylic dome chamber and YSI Sonde (model 6600 or EXO) dissolved oxygen probe in series (Figure 3.3A). Chambers then had substrate placed inside that was representative of the site area and were arranged to cover within site variability (Figure 3.3B). A 100 pebble count was used to characterize substrate size at each site following the Canadian Aquatic Biomonitoring Network (CABIN) field protocol (Reynoldson et al., 2007). At coarse substrate sites, five cobbles (with an intermediate axis approximately 5$10 \mathrm{~cm}$ in length) were selected, placed on a base and sealed inside each chamber. In contrast, at fine substrate sites chambers were pushed into the sediment to isolate an area of the streambed. Chambers were flushed daily for 10 minutes with fresh river water to limit nutrient depletion and oxygen supersaturation within the chambers during the sampling period (Grace \& Imberger, 2006). Dissolved oxygen and temperature were measured at 10 minute intervals throughout the duration of a deployment using an optical sensor on a YSI Sonde (model 6600 or EXO). 
A

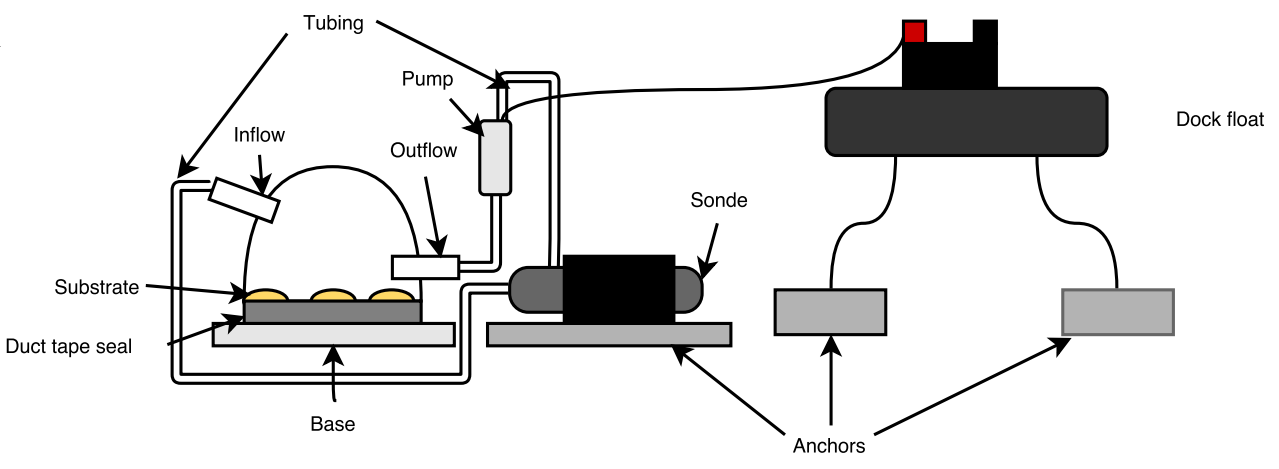

B
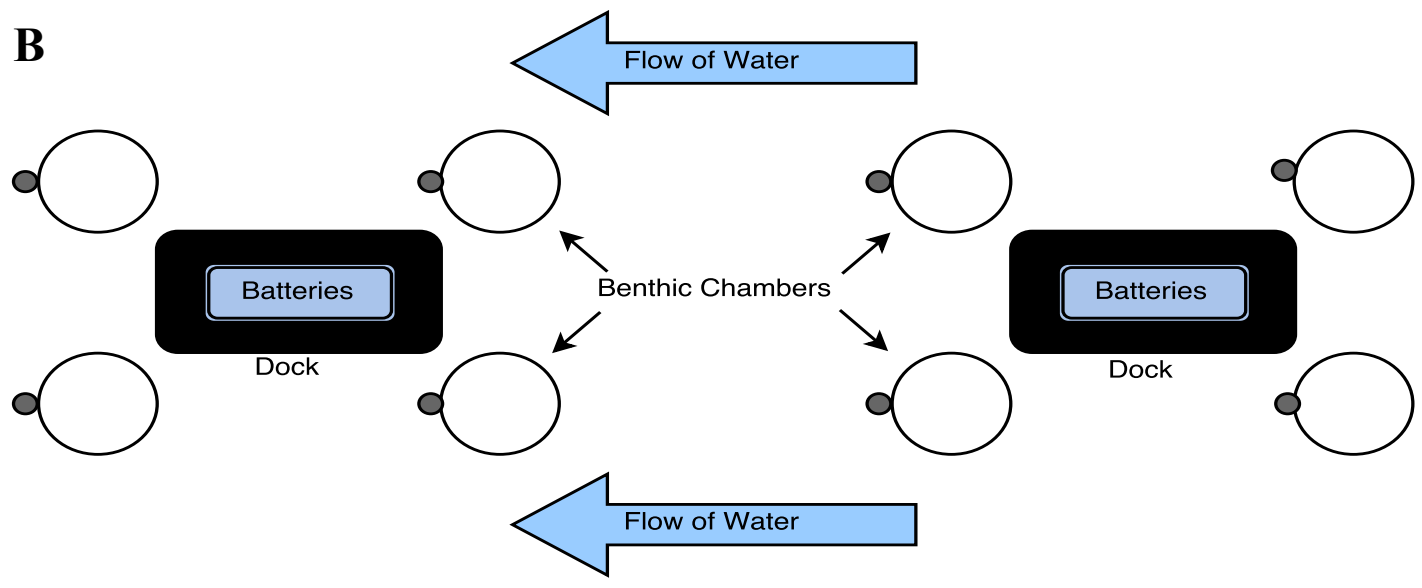

Figure 3.3. (A) Typical organization of a closed-base benthic chamber system for cobble measurements. Once the cobble substrate is placed inside, the benthic chamber is sealed with a plastic base and duct tape. The outflow of the chamber is connected to a Whale inline centrifugal pump that pumps water through an YSI Sonde (model 6600 or EXO) and back into the chamber through the inflow, which is all connected in series. A dock float was used to hold batteries that powered the pump.

(B) An overhead view of the distribution of benthic chambers at each sampling site. Four chambers were placed around each dock and arranged to cover variability within each sampling patch. 
Benthic metabolism was calculated using the following relationship between dissolved oxygen and metabolism (Grace \& Imberger, 2006):

$\Delta \mathrm{DO}=\mathrm{GPP}-\mathrm{CR}$

Equation 1

Where:

$\Delta \mathrm{DO}$ is the change in dissolved oxygen during 10-minute intervals

GPP is gross primary productivity

$\mathrm{CR}$ is community respiration

To convert dissolved oxygen measurements from volume units into areal units, photosynthetically active surface area and volume of water within the chambers were measured. Chamber volume was calculated differently for substrate types: coarse substrate was calculated by subtracting the cobble volume from the volume of an empty dome; fine substrate volume depended how deep the chamber was inserted into the sediment, volume of the chamber was subtracted from the volume of sediment in the chamber (Grace \& Imberger, 2006). Cobble volume was determined by measuring an average volume from 80 cobble samples per site and averaging the amount of water displaced from a graduated container (Grace \& Imberger, 2006). Photosynthetically active surface of the chamber was calculated for soft substrate sites using equation 2 :

Surface area $=\pi r^{2}$

Equation 2

Where:

$r$ is the radius of the chamber in meters

Surface area of cobble substrates was determined by wrapping the cobbles in aluminum foil to cover the rock and using a weight-area relationship. Cobble surface area was then divided by two, as the photosynthetically active area of cobbles is assumed to be half of the total area (Grace \& Imberger, 2006). Daily respiration rates were estimated from the mean respiration rate $(\mathrm{R})$. $\mathrm{R}$ was calculated as the mean of the change in night time DO rates, this was done by plotting a DO vs time graph and finding a six hour time 
period when DO was in a constant decline. Daily respiration was then calculated using the equation:

$\mathrm{CR}\left(\mathrm{g} \mathrm{O}_{2} \mathrm{~m}^{-2} \mathrm{~d}^{-1}\right)=$

$\mathrm{R} x$ chamber volume x 24 / photosynthetically active surface area / 1000 Equation 3

Where:

$\mathrm{R}$ is the mean respiration rate in $\mathrm{mg} \mathrm{O}_{2} \mathrm{~L}^{-1} \mathrm{hr}^{-1}$

Chamber volume is in $\mathrm{L}$

Photosynthetically active surface area is in $\mathrm{m}^{2}$

GPP was calculated as the sum of DO production during daylight hours plus DO consumed by respiration during the night time. GPP was then calculated for an area using equation 4.

$\operatorname{GPP}\left(\mathrm{g} \mathrm{O}_{2} \mathrm{~m}^{-2} \mathrm{~d}^{-1}\right)=$

$\Sigma \mathrm{GPP}_{\text {flux }} \mathrm{x}$ chamber volume $\mathrm{x} 24$ / photosynthetically active surface area / 1000 Equation 4

Where:

$\Sigma \mathrm{GPP}_{\text {flux }}$ is in $\mathrm{mg} \mathrm{O}_{2} \mathrm{~L}^{-1} \mathrm{hr}^{-1}$

Chamber volume is in $\mathrm{L}$

Photosynthetically active surface area is in $\mathrm{m}^{2}$

Net daily metabolism was calculated as the difference between GPP and CR using equation 5 .

$\mathrm{NDM}=\mathrm{GPP}-\mathrm{CR}$

Equation 5

Where:

NDM is Net daily metabolism in $\mathrm{g} \mathrm{O}_{2} \mathrm{~m}^{-2} \mathrm{~d}^{-1}$ 


\subsubsection{Physicochemical Characteristics}

Physicochemical characteristics known to influence benthic metabolism were measured to describe sampling sites and help interpret findings. Flow velocity was measured daily in the centre of the sampling site using a Sontek Flow Tracker Handheld Acoustic Doppler Velocimeter. Photosynthetically active radiation (PAR) was measured at 10 minute intervals using two Odyssey PAR Light Loggers (model Z412) per site, one that was secured underwater at substrate depth and the other at the surface of the water with both located in the centre of each sampling site. One grab water sample was collected during each sampling period for each of the experiments on the third day of deployment, by wading into the centre of the measurement locations of a site and immersing the bottle into the flow at $60 \%$ water depth. All water samples were collected in polyethylene bottles, stored at $4{ }^{\circ} \mathrm{C}$ in a cooler and transported to the Biogeochemical Analytical Services Laboratory (University of Alberta) in Edmonton, Alberta for analyses. Water samples were analyzed for nitrate-nitrite, ammonia, total nitrogen, total Kjeldahl nitrogen, total phosphorus, soluble reactive phosphorus and dissolved organic carbon concentrations (Appendix 2).

Following each experiment, organic matter and algal biomass were collected from inside each chamber to aid in interpretation of differences in primary productivity between sampling locations. Periphyton biomass (ash-free dry mass and chlorophyll- $a$ ) was estimated by scraping biomass from the substrate surface to quantify variability within the chambers (Fellows et al., 2006). At soft sediment sites, small sediment cores were taken to collect algae (Fellows et al., 2006). Organic biomass was measured using the ash-free dry mass method where biomass samples were dried overnight in an $80^{\circ} \mathrm{C}$ drying oven, the samples weighed, placed in a $500^{\circ} \mathrm{C}$ oven and then reweighed. Chlorophyll- $a$ was measured at fine sediment sites by extracting chlorophyll- $a$ from sediment cores by adding $10 \mathrm{~mL}$ of $95 \%$ ethanol and then boiling for 7 minutes inside a hot water bath set at $80^{\circ} \mathrm{C}$. After boiling, samples were left to cool in the dark for 30 minutes and then centrifuged. Chlorophyll- $a$ extract volume was then recorded and $1 \mathrm{~mL}$ was transferred into a Turner Designs Trilogy Lab Fluorometer (Model 7200-000) and 
measured. For cobble substrate, scrapings were emptied into a blender and contents were blended for 1 minute to make a homogeneous solution. Afterwards, 1-10 mL of the solution was then filtered onto a Whatman Glass Fibre Filter and $10 \mathrm{~mL}$ of $90 \%$ ethanol was added. Chlorophyll- $a$ was then extracted and measured following the same process as for the sediment cores.

\subsection{Data Analysis}

All benthic metabolism parameters were tested for normality using the ShapiroWilk test. Parameters not normally distributed were log transformed to improve variable normality for analysis. GPP and CR were calculated for each chamber for each day and the daily mean of all chambers calculated. A one-way ANOVA was conducted to test for effects of chamber location on stream metabolism. As no significant effects $(p>0.05)$ of chamber location were detected metabolism measurements from all chambers for each sampling period were pooled for further analysis. A General Linear Model (GLM) was used to assess differences associated with site comparisons for assessments 1 through 4: 1) to examine changes between coarse and fine substrate patches among months; 2) to investigate potential differences among channel location (main and side channel) among months; 3) to assess potential differences between low-head and medium-head regulated river substrate patches among months, and; 4) to evaluate potential temporal differences among sampling weeks. GLM results were considered significant if the interaction term of the model was $(p \leq 0.01)$. For assessments 1 through 3 , in the cases where a significant interaction term was not identified a second GLM was carried out to determine differences in metrics of stream metabolism (i.e., GPP, CR and NDM) between sites for each individual month. For assessment 4 , in the case where pairwise differences between individual weeks could not be identified, a polynomial regression with a quadratic function was used to determine if a significant temporal trend was present over the sampling periods. Systat 13 (Systat Software Inc. 2015) was used for all ANOVA and GLM analyses. 
Multiple linear regressions were calculated using MuMIn package in $\mathrm{R}$ to evaluate $a$ priori hypothesis about the relationships of GPP, CR and NDM to environmental variables known to influence stream metabolism (i.e., water temperature, bed PAR, water depth fluctuation) for assessment 4. Error residual sums of squares for each multiple linear regression were used to calculate a corrected Akaike Information Criteria $\left(\mathrm{AIC}_{\mathrm{c}}\right)$ (Burnham \& Anderson, 2002). For GPP, CR and NDM, 10 a priori models were deduced (see Appendices 3, $4 \&$ 5). Candidate models, including null (intercept only) and global models were ranked using Akaike Information Criterion (AIC) (Akaike, 1973; Burnham \& Anderson, 2002). The best model had the lowest AICc value as compared to the other candidate models. However, competing models with $\Delta \mathrm{AIC}_{\mathrm{c}}<7\left(\Delta \mathrm{AIC}_{\mathrm{c}}\right.$ being the difference between the best ranking and competing models) were considered to be valid and plausible models that can contain relevant information (Anderson, 2008). In this group of best models, more complex, lower-ranked models were removed if the model differed by approximately 2 AICc units per additional parameter (i.e., 2, 4 or 6 units for models with 1 to 3 added parameters) because additional parameters are considered inconclusive (Arnold, 2010). If more complex models were removed, weights of the remaining models were then recalculated. Akaike weights, evidence ratios, standard errors and $85 \%$ confidence intervals were used to make inferences about the relative support for competing models (Burnham \& Anderson 2002; Anderson, 2008; Arnold, 2010). Model averaging of parameter estimates was conducted for the GPP models within $7 \Delta \mathrm{AIC}_{\mathrm{c}}$ of the top model to determine which factors had the strongest effect on primary production (Grueber et al., 2011). Model averaging was not required to establish the best models for either CR or NDM. 


\subsection{Results}

\subsection{Assessment 1: River Substrate}

Physical parameters increased as summer progressed at both sites, but was generally greater in sand substrate. Mean daily water temperatures were coldest in June ( cobble $=14.7^{\circ} \mathrm{C}$; sand $=15.1^{\circ} \mathrm{C}$ ) and warmest in August $\left(\right.$ cobble $=22.4^{\circ} \mathrm{C}$; sand $=$ $22.5^{\circ} \mathrm{C}$ ) at both sites (Table 4.1). Mean PAR at the river bed was nearly six times greater at the cobble site than the sand in June, however, the sand site received more than double the amount of bed PAR in both July and August. Mean PAR at the river surface was greatest in August for both sites. Concentration of $\mathrm{NH}_{3}$ at the cobble site was over six times greater than in sand for the August sample, however; concentrations were within 15 $\mu \mathrm{g} / \mathrm{L}$ for the other two sample periods (Table 4.2). $\mathrm{NO}_{2}+\mathrm{NO}_{3}$ was greatest in June at both sites, but sites did not differ by more than $13 \mu \mathrm{g} / \mathrm{L}$ for any sampling event. TN differed the most between sites in June as the cobble sample had more than double the TN that was observed at the sand site. A large difference in TN was also measured in August when the cobble sample was $206 \mu \mathrm{g} / \mathrm{L}$ greater than the sand sample. Similarly, TKN was at least $60 \%$ greater at the cobble site for both June and August with the largest concentration occurring in June at $708 \mu \mathrm{g} / \mathrm{L}$. SRP ranged from 2 to $3 \mu \mathrm{g} / \mathrm{L}$ and 2 to 4 $\mu \mathrm{g} / \mathrm{L}$ at cobble and sand sites, respectively. TP in sand was twice the concentration observed in cobble for the month of July, whereas sites differed by no more than $1 \mu \mathrm{g} / \mathrm{L}$ in June and August. DOC differed by no more than $0.5 \mathrm{mg} / \mathrm{L}$ between sites in for any of the three sampling events. Differences in chlorophyll-a concentrations between sites became more pronounced as the summer progressed, as sand concentrations were greater by $20 \%$ in June, $400 \%$ greater in July and over $3000 \%$ greater in August. AFDM in cobble was double and triple what was observed in the sand site in July and June, respectively. However, AFDM in sand substrate was over twice the amount found in cobble for the month of August.

GPP increased from June to August in both substrates, ranging from 1.9 to $3.8 \mathrm{~g}$ $\mathrm{O}_{2} \mathrm{~m}^{-2} \mathrm{~d}^{-1}$ and 0.1 to $1.8 \mathrm{~g} \mathrm{O}_{2} \mathrm{~m}^{-2} \mathrm{~d}^{-1}$ at the cobble and sand sites, respectively (Figure 4.1A). CR ranged from 0.3 to $0.9 \mathrm{~g} \mathrm{O}_{2} \mathrm{~m}^{-2} \mathrm{~d}^{-1}$ in cobble and 0.1 to $0.9 \mathrm{~g} \mathrm{O}_{2} \mathrm{~m}^{-2} \mathrm{~d}^{-1}$ in sand 
(Figure 4.1B). Mean NDM was negative in sand substrate for June (-0.05 $\left.\mathrm{g} \mathrm{O}_{2} \mathrm{~m}^{-2} \mathrm{~d}^{-1}\right)$ and July $\left(-0.4 \mathrm{~g} \mathrm{O}_{2} \mathrm{~m}^{-2} \mathrm{~d}^{-1}\right)$, but not August $\left(0.9 \mathrm{~g} \mathrm{O}_{2} \mathrm{~m}^{-2} \mathrm{~d}^{-1}\right)$, whereas NDM was positive in all three months ranging from 1.6 to $2.9 \mathrm{~g} \mathrm{O}_{2} \mathrm{~m}^{-2} \mathrm{~d}^{-1}$ at the cobble site (Figure 4.1C). GLMs revealed an interaction between substrate type and month for GPP $(\mathrm{F}=7.4 ; \mathrm{p}=$ $0.003)$ and $\operatorname{NDM}(F=4.09 ; p=0.025)$, but not $C R(F=1.6 ; p=0.212)$ (Figure 4.1). Posthoc analysis showed that GPP was greater at the cobble site than the sand site in June ( $\mathrm{p}=$ $0.038)$ and July $(\mathrm{p}<0.001)$, but not August $(\mathrm{p}=0.26)$. However, NDM was greater at the cobble site in all three months (June, $p=0.001$; July, $p<0.001$; August, $p<0.001$ ). Subsequent one-way GLMs assessing between site differences in CR indicated greater $\mathrm{CR}$ at the cobble site in June $(\mathrm{F}=5.6 ; \mathrm{p}=0.034)$ but no difference in July $(\mathrm{F}=2.1 ; \mathrm{p}=$ $0.18)$ or August $(\mathrm{F}=0.01 ; \mathrm{p}=0.92)$. 


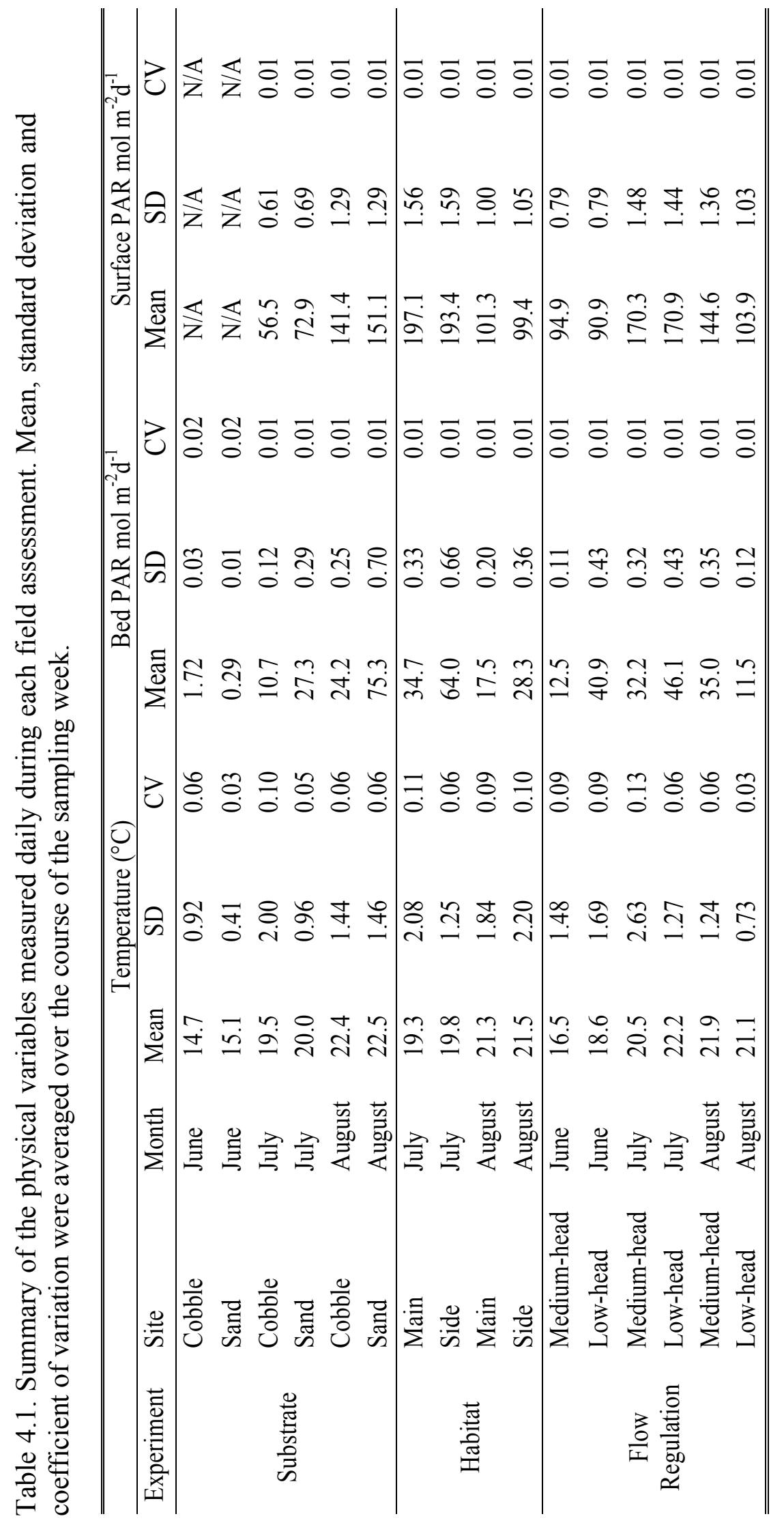




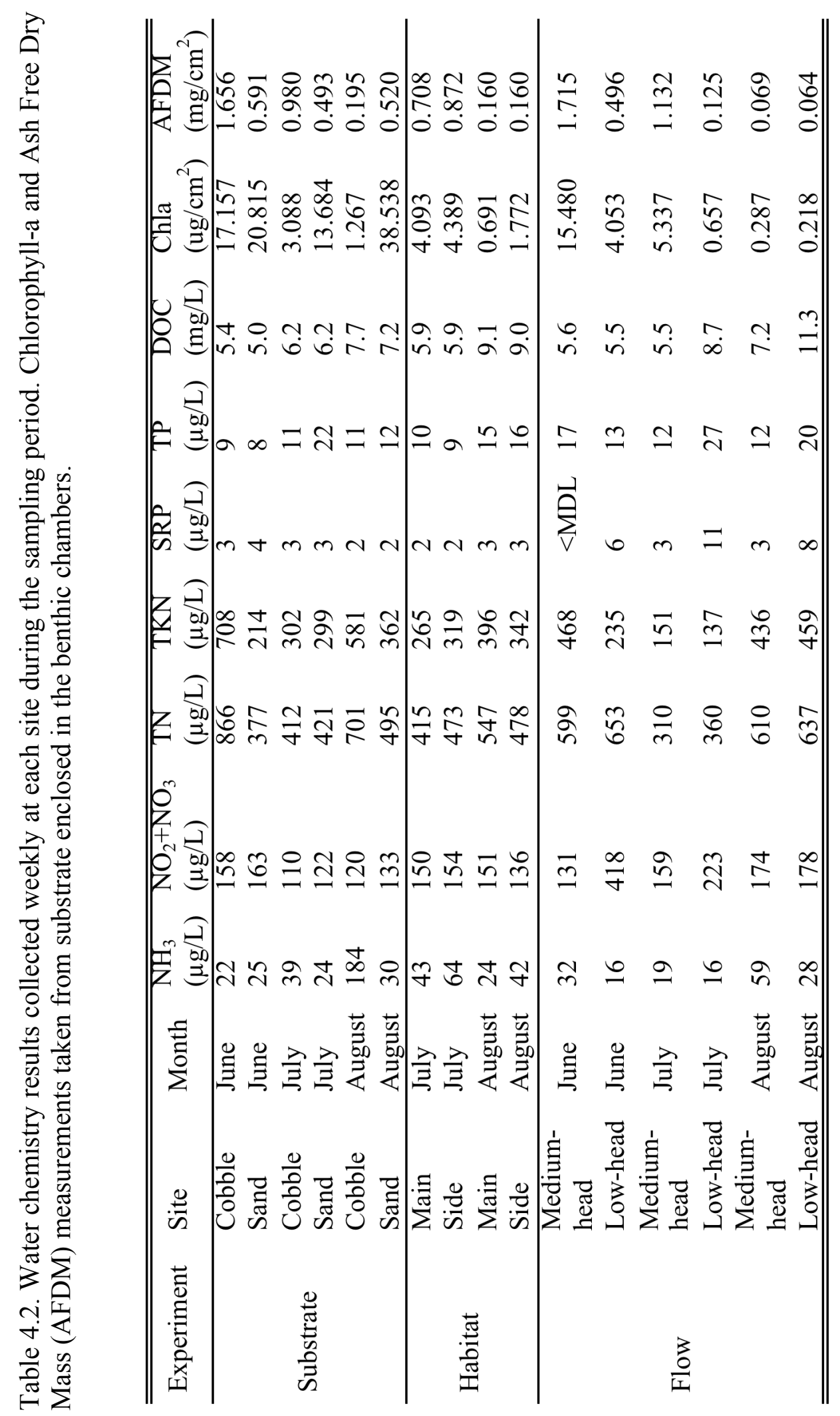



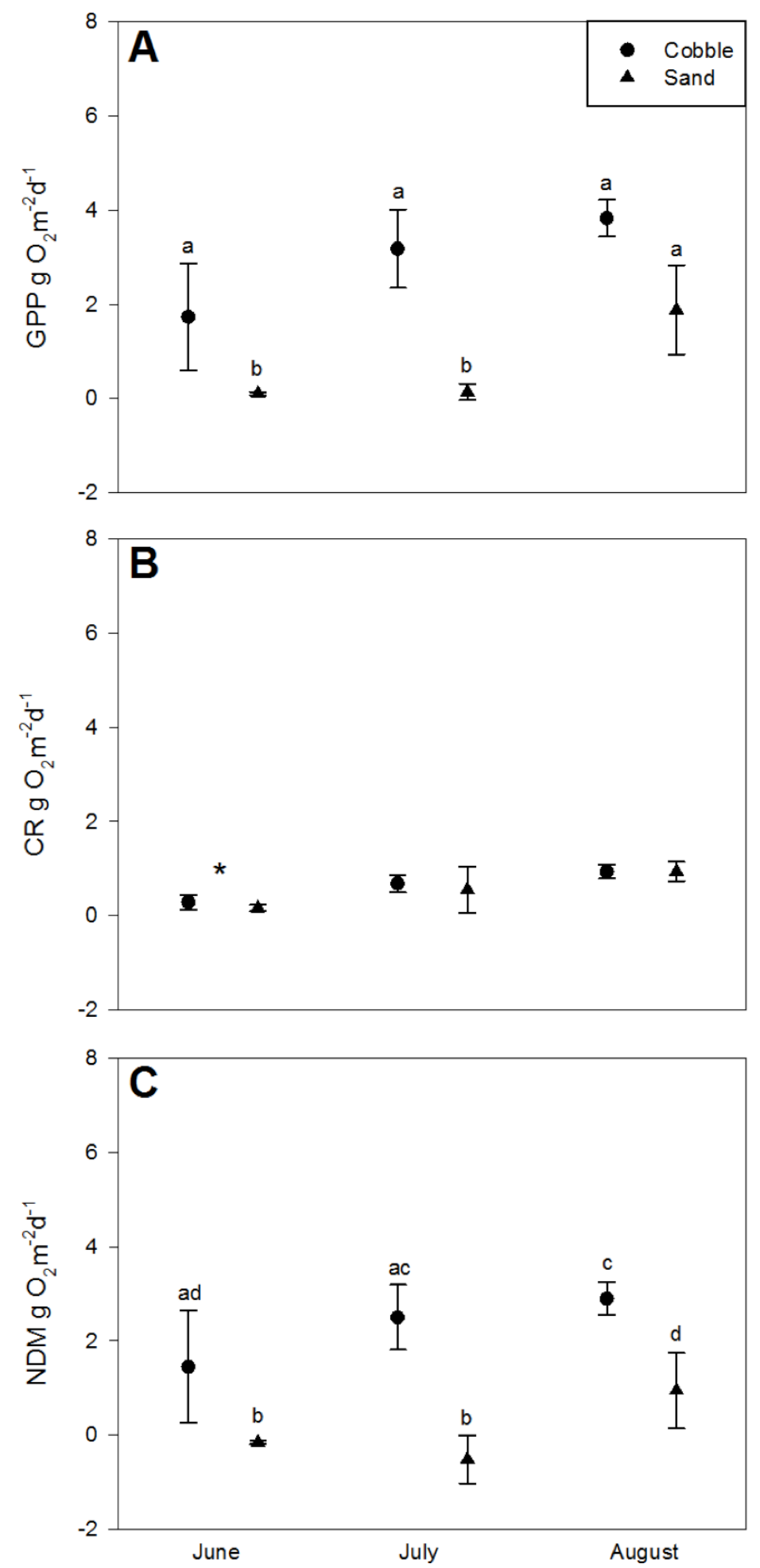

Figure 4.1. Average gross primary productivity (GPP) (A), community respiration (CR) (B), and net daily metabolism (NDM) (C) ( \pm standard deviation) measured as benthic metabolism rates between coarse and fine substrate patches during the summer of 2016. Letters denote post-hoc analysis similarity and differences in cases where an interaction was present. The * represent differences from GLM. 


\subsection{Assessment 2: Channel Location}

Water temperature was consistently within $1{ }^{\circ} \mathrm{C}$ at the main and side channel sites (Table 4.1.), with the minimum mean temperatures in July at $19.3^{\circ} \mathrm{C}$ and $19.8^{\circ} \mathrm{C}$ and maximum mean in August at $21.3^{\circ} \mathrm{C}$ and $21.5^{\circ} \mathrm{C}$, for the main and side channel sites, respectively. Mean bed PAR values indicated $62 \%$ and $84 \%$ more light penetration in the side channel in July and August, respectively. In contrast, mean surface PAR values were within $5 \mathrm{~mol} \mathrm{~m}^{-2} \mathrm{~d}^{-1}$ for both sampling weeks. Concentrations of $\mathrm{NH}_{3}$ for the samples taken at the side channel site were nearly 50\% greater in July and 75\% greater in August than at the main channel site. $\mathrm{NO}_{2}+\mathrm{NO}_{3}$ was within $1 \mu \mathrm{g} / \mathrm{L}$ for the two samples collected in the main channel, whereas side channel samples differed by $18 \mu \mathrm{g} / \mathrm{L}$ (Table 4.2). Both TN and TKN were larger in the side channel during the July sample and exhibited the largest concentrations in August for the main channel site. SRP concentrations were identical at main and side channel sites for both July $(2 \mu \mathrm{g} / \mathrm{L})$ and August $(3 \mu \mathrm{g} / \mathrm{L})$. TP values did not differ between sites by more than $1 \mu \mathrm{g} / \mathrm{L}$ in both July and August, with the lowest concentrations for both sites occurring in July. Similarly, DOC concentration was identical at both sites in July and only differed by $0.1 \mathrm{mg} / \mathrm{L}$ in August. Chlorophyll- $a$ measurements were similar during the July sampling period as side channel biomass was only $7.5 \%$ greater than the main channel. The side channel site had approximately $140 \%$ more chlorophyll- $a$ than the main channel in August. The side channel had nearly 25\% more organic matter than the main channel in July, but site AFDM was identical in August.

GPP at main channel ranged from 3.4 to $5.4 \mathrm{~g} \mathrm{O}_{2} \mathrm{~m}^{-2} \mathrm{~d}^{-1}$, CR from 0.7 to 0.8 and NDM from 2.1 to $3.2 \mathrm{~g} \mathrm{O}_{2} \mathrm{~m}^{-2} \mathrm{~d}^{-1}$. Side channel GPP ranged from 3.4 to $5.4 \mathrm{~g} \mathrm{O}_{2} \mathrm{~m}^{-2} \mathrm{~d}^{-1}$, CR from 1.0 to $1.2 \mathrm{~g} \mathrm{O}_{2} \mathrm{~m}^{-2} \mathrm{~d}^{-1}$, and NDM from 2.4 to $4.1 \mathrm{~g} \mathrm{O}_{2} \mathrm{~m}^{-2} \mathrm{~d}^{-1}$ (Figure 4.2). The GLMs examining effects of channel location and month did not identify a significant interaction term for GPP $(\mathrm{F}=0.5 ; \mathrm{p}=0.462), \mathrm{CR}(\mathrm{F}=0.8 ; \mathrm{p}=0.364)$ or $\mathrm{NDM}(\mathrm{F}=2.0 ; \mathrm{p}$ $=0.166$ ) (Figure 4.2). GLMs assessing between site differences also found no difference of GPP in July $(\mathrm{F}=1.6, \mathrm{p}=0.218)$ or August $(\mathrm{F}=0.04, \mathrm{p}=0.83)$ (Figure 4.2A). Similarly, NDM was not different in July $(\mathrm{F}=1.4, \mathrm{p}=0.248)$ or August $(\mathrm{F}=0.7, \mathrm{p}=$ 0.417 ) (Figure $4.2 \mathrm{C}$ ). $\mathrm{CR}$ was $60 \%$ greater in the side channel during July $(\mathrm{F}=6.6$; $\mathrm{p}$ - 
value $=0.021)$, but no difference was detected in August $(\mathrm{F}=2.3, \mathrm{p}=0.147)$ (Figure 4.2B). 

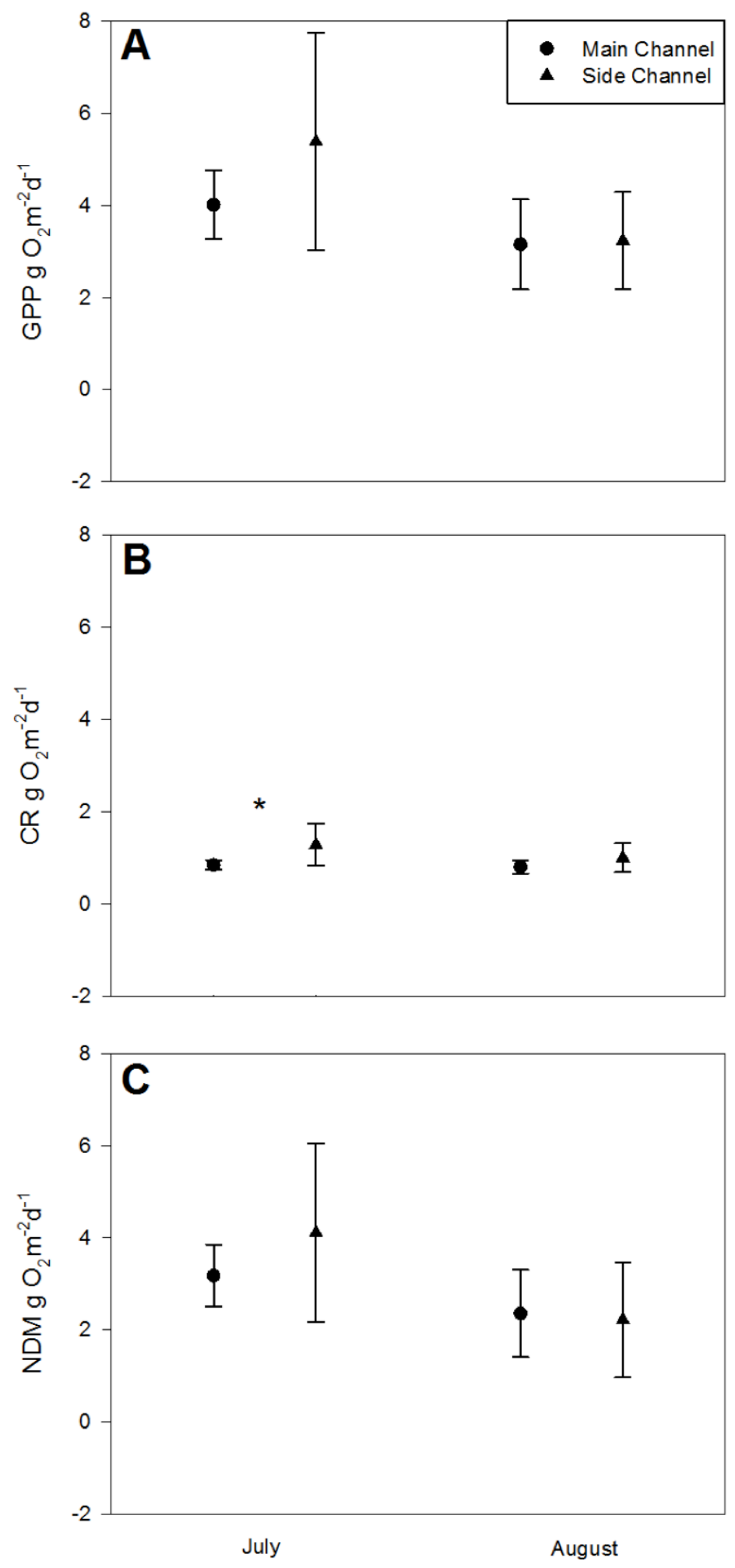

Figure 4.2. Average gross primary productivity (GPP) (A), community respiration (CR) (B), and net daily metabolism (NDM) (C) ( \pm standard deviation) measured as benthic metabolism rates between main and side channel patches during the summer of 2016. Letters denote post-hoc analysis similarity and differences in cases where an interaction was present. The * represents a significant difference between sites. 


\subsection{Assessment 3: Flow Regulation}

Mean water temperature was approximately $2^{\circ} \mathrm{C}$ higher at the low-head site during both June and July, whereas in August the medium-head site was less than $1{ }^{\circ} \mathrm{C}$ warmer (Table 4.1). The largest between site differences of mean bed PAR occurred in June, as substrate at the medium-head site received approximately 70\% less PAR than the low-head site. In contrast, during August sampling the low-head site bed PAR values were $67 \%$ less. July had the smallest difference between sites with the medium-head site receiving 30\% less bed PAR than the low-head site. Mean surface PAR was similar between sites in both June and July, never differing by more than $4.0 \mathrm{~mol} \mathrm{~m}^{-2} \mathrm{~d}^{-1}$. The greatest mean values for both sites occurred during the July sampling. During the August sampling surface PAR was $40 \%$ greater at the medium-head site. The greatest $\mathrm{NH}_{3}$ concentrations were measured in August for both sites (Table 4.2). $\mathrm{NH}_{3}$ concentrations at the medium-head site were double those of the low-head site in June and August. $\mathrm{NO}_{2}+\mathrm{NO}_{3}$ concentrations were greater at the low-head site for each sample taken, however, the difference between sites decreased from $287 \mu \mathrm{g} / \mathrm{L}$ in June, and $64 \mu \mathrm{g} / \mathrm{L}$ in July to only $4 \mu \mathrm{g} / \mathrm{L}$ in August. Similar to $\mathrm{NO}_{2}+\mathrm{NO}_{3}, \mathrm{TN}$ concentrations were greatest at the low-head site for all three sampling events. However, the difference in TN concentration between the two sites did not exceed $43 \mu \mathrm{g} / \mathrm{L}$ for any sampling event. TKN differed the most between sites in June as the medium-head site had nearly double the concentration of the low-head site. TKN did not differ by more than $24 \mu \mathrm{g} / \mathrm{L}$ between sites in July and August. SRP was greatest in the low-head reach for all three sampling events and concentrations were at least double that measured at the medium-head site. TP measurement was larger at the medium-head site in June, but higher concentrations were measured at the low-head site in both July and August, with over twice the amount of TP observed at the low-head site in July. DOC was greatest at the low-head sites in all samples but the one collected in June when the medium-head site sample was $0.1 \mathrm{mg} / \mathrm{L}$ greater than the low-head sample. The largest and smallest DOC concentrations were observed in the August and June samples at both sites. Chlorophyll- $a$ at the medium-head site was approximately $280 \%$ larger in June, $660 \%$ larger in July but only $30 \%$ greater in 
August. AFDM ranged from 0.07 to $1.72 \mathrm{mg} / \mathrm{cm}^{2}$ and 0.06 to $0.49 \mathrm{mg} / \mathrm{cm}^{2}$ at the medium-head and low-head sites, respectively.

GPP at the medium-head site ranged from 3.2 to $4.6 \mathrm{~g} \mathrm{O}_{2} \mathrm{~m}^{-2} \mathrm{~d}^{-1}$, CR from 0.6 to $1.2 \mathrm{~g} \mathrm{O}_{2} \mathrm{~m}^{-2} \mathrm{~d}^{-1}$ and NDM from 2.5 to $3.3 \mathrm{~g} \mathrm{O}_{2} \mathrm{~m}^{-2} \mathrm{~d}^{-1}$ (Figure 4.3). The low-head site GPP ranged from 2.1 to $3.7 \mathrm{~g} \mathrm{O}_{2} \mathrm{~m}^{-2} \mathrm{~d}^{-1}$, CR from 0.5 to $0.8 \mathrm{~g} \mathrm{O}_{2} \mathrm{~m}^{-2} \mathrm{~d}^{-1}$, and NDM from 1.6 to $2.9 \mathrm{~g} \mathrm{O}_{2} \mathrm{~m}^{-2} \mathrm{~d}^{-1}$ (Figure 4.3). Comparison of benthic metabolism at the mediumhead and low-head sites revealed an interaction effect of site and month for CR ( $\mathrm{F}=4.8$; $\mathrm{p}=0.014)$, but not GPP $(\mathrm{F}=2.2 ; \mathrm{p}=0.115)$ or NDM $(\mathrm{F}=1.8, \mathrm{p}=0.164)$ (Figure 4.3). Post-hoc analysis revealed that CR differed between sites in the month of July ( $p=0.025)$ with $\mathrm{CR}$ at the medium-head site being 62\% larger than $\mathrm{CR}$ at the low-head site (Figure 4.3B). No differences were observed in CR in June $(p=0.849)$ or August $(p=0.622)$. Individual GLMs comparing GPP between medium-head and low-head sites for each month revealed that GPP was greater at the medium-head site in July ( $F=14.2 ; \mathrm{p}=$ $0.002)$ and August $(F=37.1 ; p=<0.001)$ but not in June $(F=0.8 ; p=0.77)$ (Figure 4.3A). NDM followed the same trend as GPP as the medium-head site was greater in July $(\mathrm{F}=5.9 ; \mathrm{p}=0.031)$ and August $(\mathrm{F}=24.1 ; \mathrm{p}<0.001)$ but not June $(\mathrm{F}=0.007 ; \mathrm{p}=0.933)$ (Figure 4.3C). 

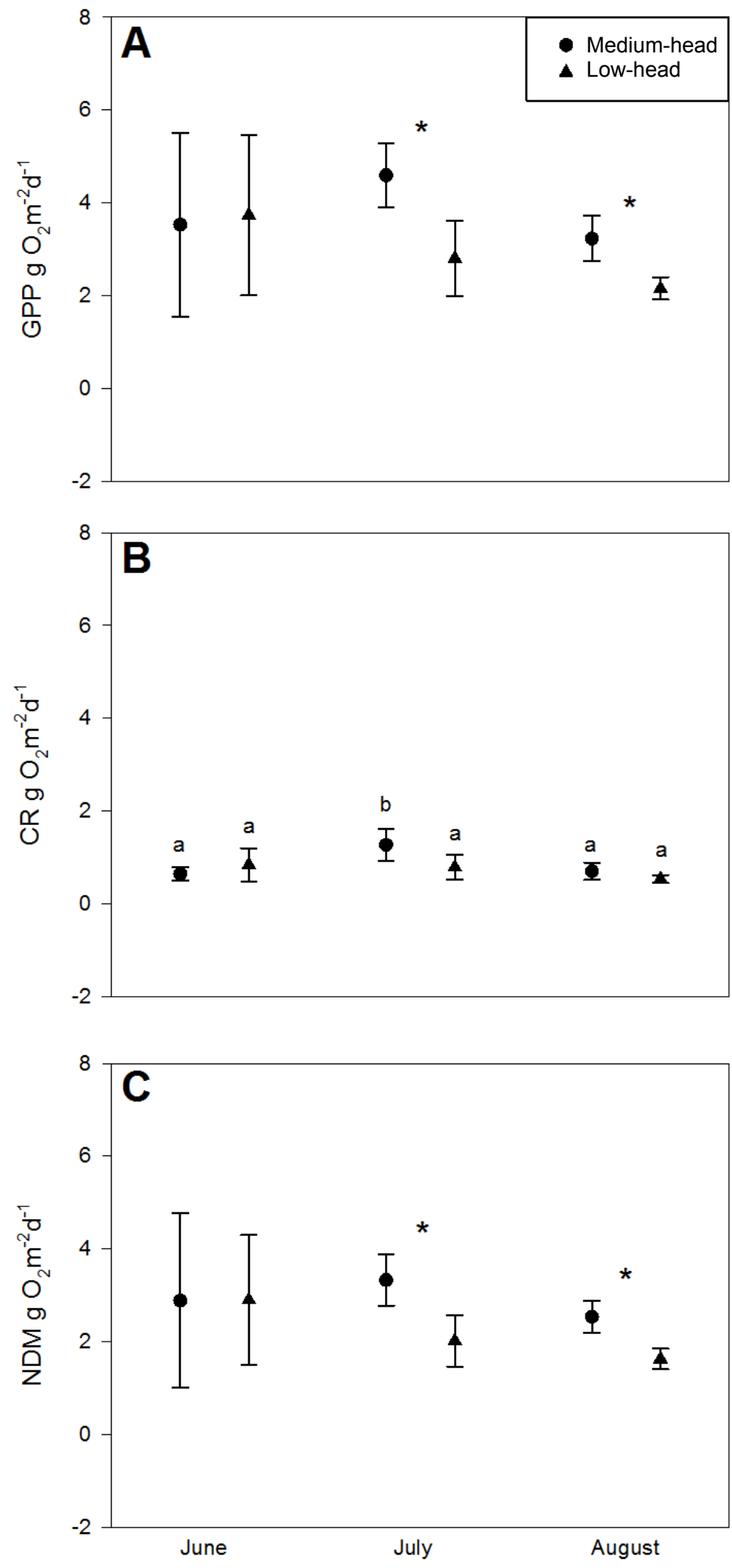

Figure 4.3. Average gross primary productivity (GPP) (A), community respiration (CR) (B), and net daily metabolism (NDM) (C) ( \pm standard deviation) measured as benthic metabolism rates coarse substrate patches in a medium-head and low-head reach. Letters denote post-hoc analysis similarity and differences when an interaction was present. The * represents a difference between sites from the GLM. 


\subsection{Assessment 4: Temporal Variation}

From June through August, mean daily water temperature ranged from 14.7$22.4^{\circ} \mathrm{C}$ (Figure 4.4). Week 1 had the lowest temperature, but temperature generally trended upwards until its peak in week 6, followed by a slight decrease through completion of sampling in week 8 . The greatest change in temperature occurred between weeks 2 and 3 when mean temperature increased by $3^{\circ} \mathrm{C}$. Mean bed PAR increased nearly ten-fold from week 1 to 2 (1.7 to $\left.12.5 \mathrm{~mol} \mathrm{~m}^{-2} \mathrm{~d}^{-1}\right)$, and over three fold from week 3 to 4 (10.7 to $\left.34.7 \mathrm{~mol} \mathrm{~m}^{-2} \mathrm{~d}^{-1}\right)$. The three largest surface PAR measurements corresponded with the three largest bed PAR measurements in weeks 4, 5 and 8 . The range of the $8 \mathrm{NH}_{3}$ samples taken over the summer was 19 to $184 \mu \mathrm{g} / \mathrm{L}$, however the maximum value observed in week 6 was more than threefold larger than the next largest measurement (59 $\mu \mathrm{g} / \mathrm{L}$ in week 8) (Figure 4.5). The week 3 sample provided the minimum concentration of $\mathrm{NO}_{2}+\mathrm{NO}_{3}$ at $110 \mu \mathrm{g} / \mathrm{L}$, with the greatest concentration measured in week 8 at $174 \mu \mathrm{g} / \mathrm{L}$. $\mathrm{TN}$ and TKN ranged from $310-866 \mu \mathrm{g} / \mathrm{L}$ and $151-708 \mu \mathrm{g} / \mathrm{L}$, respectively, over the 8 sampling events with both parameters having maximum concentrations in week 1 and minimums in week 5 . TN was at least $30 \%$ lower during the three sampling weeks in July (Weeks 4, 5 and 6), than for the samples in June and August. SRP was between 2 and 3 $\mu \mathrm{g} / \mathrm{L}$ for all weeks except week 2, which was determined to be below the minimum detection limit of the analytical method. The minimum TP concentration was observed in week 1 , and the maximum in week 2. TP concentration in weeks 3 through 8 were all within $5 \mu \mathrm{g} / \mathrm{L}$. DOC ranged from $5.4 \mathrm{mg} / \mathrm{L}$ in week 1 to $9.1 \mathrm{mg} / \mathrm{L}$ in week 7, but August samples (weeks 6, 7 and 8) had concentrations at least 16\% greater than any measurement collected in weeks 1 through 5 (Figure 4.6). Chlorophyll- $a$ concentrations decreased between weeks 1 and 2, and weeks 6 through 8 over the summer, with the greatest chlorophyll- $a$ in week $1\left(17.16 \mu \mathrm{g} / \mathrm{cm}^{2}\right)$, and lowest week $8\left(0.28 \mu \mathrm{g} / \mathrm{cm}^{2}\right)$ (Figure 4.6). However, chlorophyll- $a$ increased in consecutive sampling weeks from $3.1 \mu \mathrm{g} / \mathrm{cm}^{2}$ in week 3 to $5.3 \mu \mathrm{g} / \mathrm{cm}^{2}$ in week 5. AFDM followed a similar trend ranging from 0.06-1.72 $\mathrm{mg} / \mathrm{cm}^{2}$, with the exception of a decrease in organic mass between weeks 3 and 4 . The lowest AFDM occurred in week 8 and the maximum occurred in week 2. 
GPP and CR followed similar patterns, with minimum average daily rates observed in week 1 and maximum rates observed in week 5 (Figure 4.7 A, B). Results from the GLM indicated that differences among weeks for GPP, CR and NDM were significant $(\mathrm{F}=1.9 ; \mathrm{p}=0.085 ; \mathrm{F}=23.0 ; \mathrm{p}=<0.001, \mathrm{~F}=4.0 ; \mathrm{p}=0.002)$. Post-hoc tests revealed that $\mathrm{CR}$ in week 1 was less than all other weeks $(\mathrm{p}<0.001)$. CR in week 5 was found to be greater than CR in weeks $1(\mathrm{p}<0.001), 2(\mathrm{p}=0.001), 3(\mathrm{p}=0.002), 7(\mathrm{p}=$ $0.042)$ and $8(\mathrm{p}=0.002)$. No pairwise differences were detected between individual weeks for GPP ( $>0.1)$ however, a polynomial regression revealed a significant quadratic trend $\left(\mathrm{R}^{2}=0.75 ; \mathrm{F}=7.2 ; \mathrm{p}=0.017\right)$. NDM post-hoc results indicated NDM was less in week 1 than weeks $2(\mathrm{p}=0.005), 4(\mathrm{p}=0.007), 5(\mathrm{p}=0.002)$, and $6(\mathrm{p}=0.027)$ (Figure 4.7C).

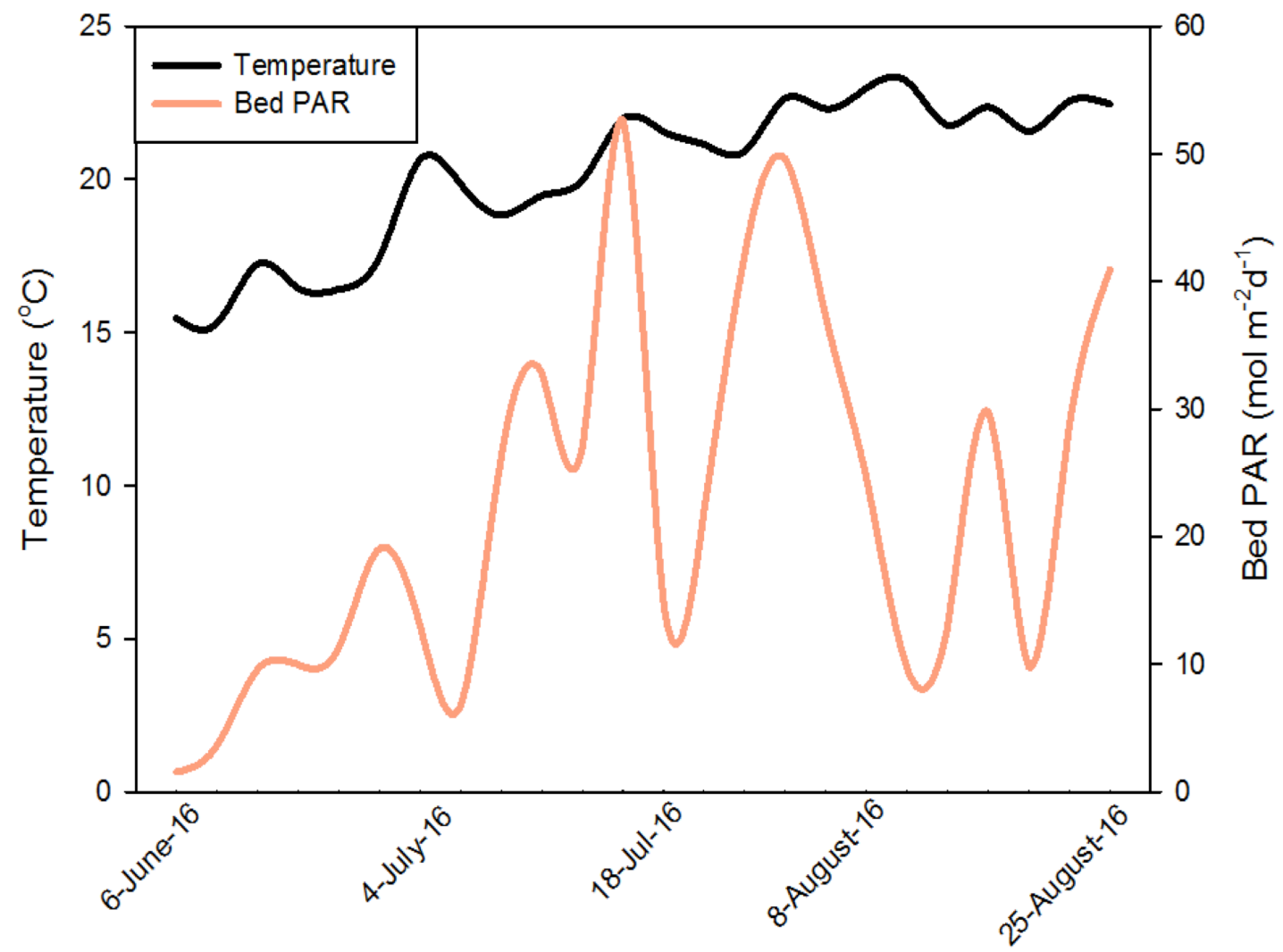

Figure 4.4. Mean daily temperature $\left({ }^{\circ} \mathrm{C}\right)$ and mean bed PAR $\left(\mathrm{mol} \mathrm{m}^{-2} \mathrm{~d}^{-1}\right)$ from each sampling period throughout the summer of 2016. 

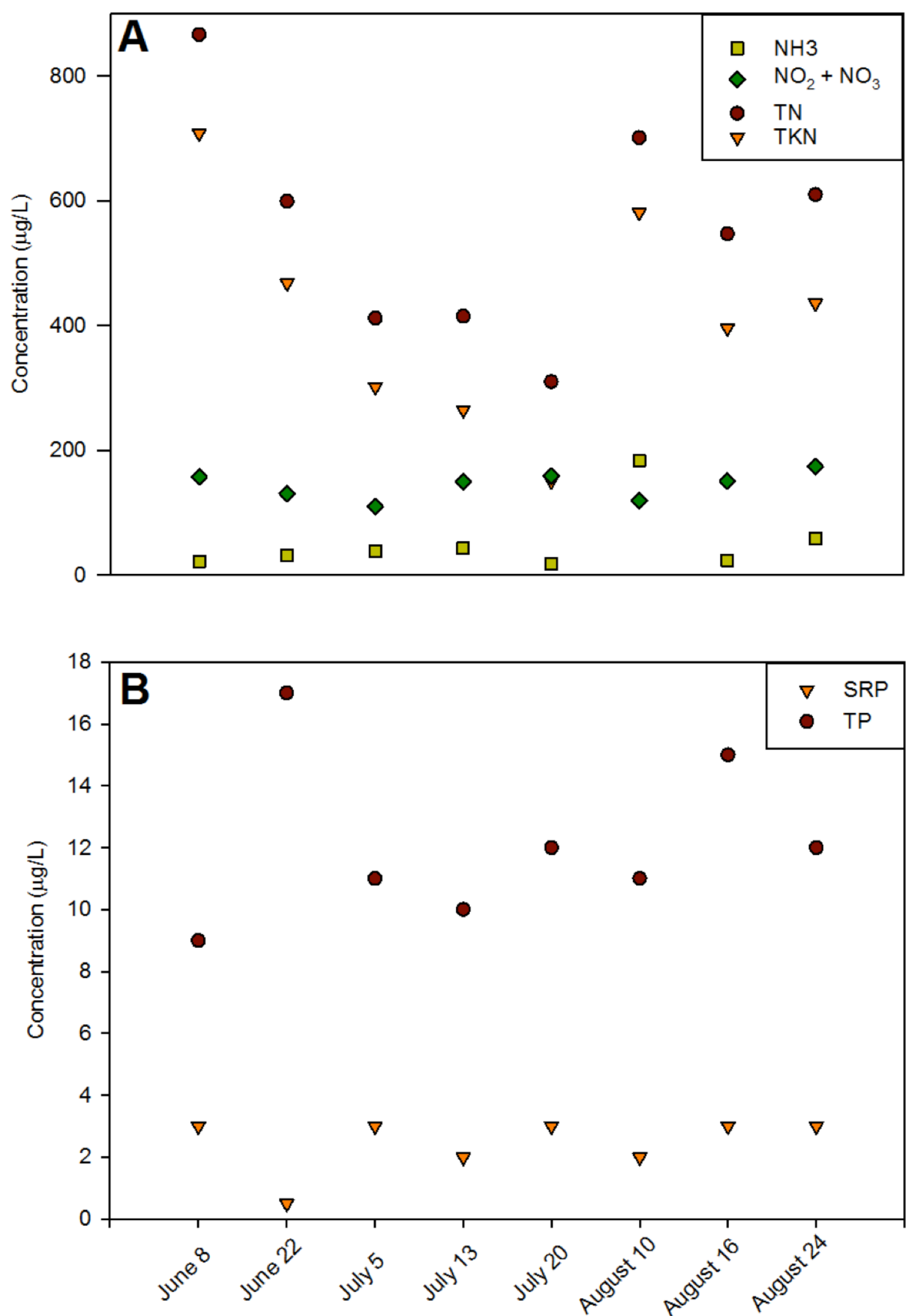

Figure 4.5.Inorganic nitrogen (A) and inorganic phosphorus (B) concentrations from once a week sampling in the Saint John River in the 2016 study period. 

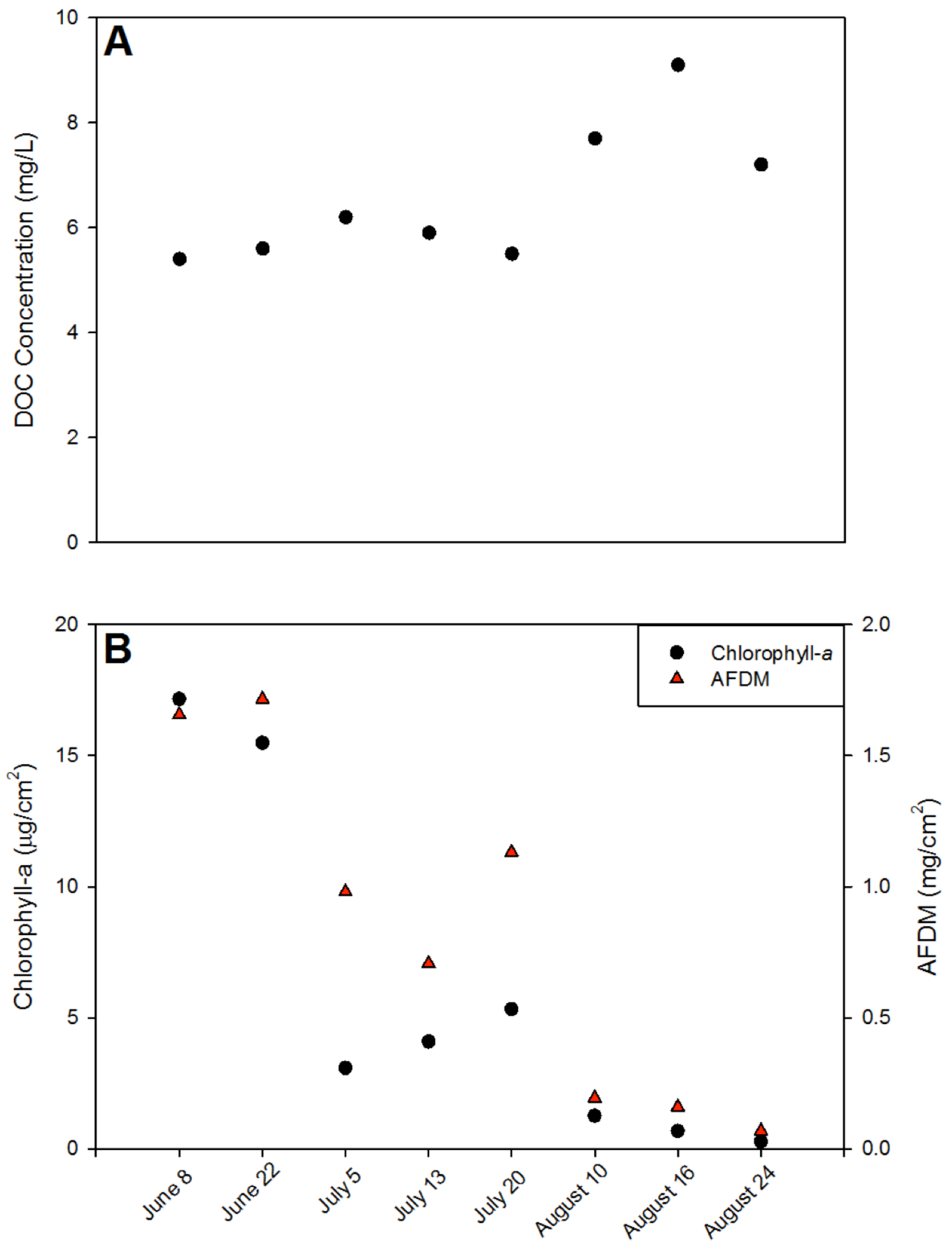

Figure 4.6. Dissolved organic carbon (A), Chlorophyll-a and ash free dry mass (B) for each sampling week during the summer of 2016. 

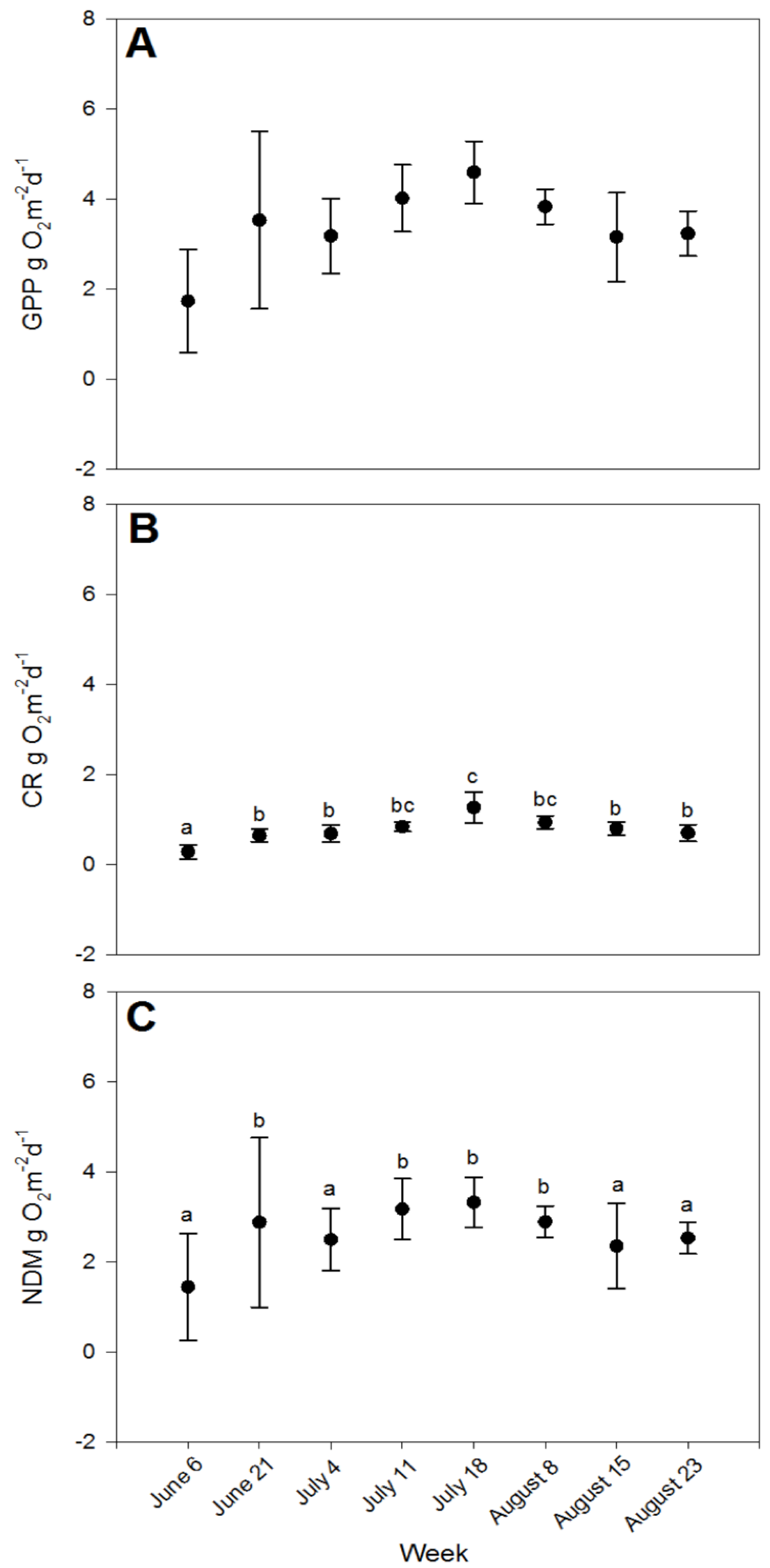

Figure 4.7. Average gross primary productivity (GPP) (A), community respiration (CR) (B), and net daily metabolism (NDM) (C) ( \pm standard deviation) measured as temporal change in benthic metabolism at a cobble substrate patch in the Saint John River during the summer of 2016. 


\subsubsection{Hypothesis Testing of Drivers of Benthic Metabolism}

GPP was best predicted by a priori GPP Model 15 (Table 4.3), which consisted of PAR, water temperature and the PAR x Temp interaction term. Model 15 had an associated adjusted $\mathrm{R}^{2}$ of 0.44 indicating nearly half the variability in GPP over the sampling period could be explained by these three variables. However, GPP Models 2, 3, 4, 7, 8 and 16 were within 7 AICc units of the top ranked model (Table 4.3). We were able to discard the more complex Model 16 as the model had a lower AICc value indicating the addition of Depth as a fourth parameter was uninformative. In contrast, Models 2, 3, 4, 7 and 8 could not be discounted, although the strength of evidence (i.e., weight) was more than 5 times greater for Model 15 than for Models 2, 7 and 8 but less than 3 times greater for Models 3 and 4. Model averaging of Models 2, 3, 4, 7, 8 and 15 indicated that GPP was positively associated with PAR (model-averaged parameter estimates \pm SE: $0.108 \pm 0.037)$ but negatively correlated with Temp $(-0.056 \pm 0.0527)$, PAR*Temp $(-0.082 \pm 0.080)$ and Depth $(-0.021 \pm 0.031)$. The negative associations between GPP and the Temp and PAR*Temp parameters were contrary to our a priori hypotheses. The negative association coupled with the model averaged standard errors of these terms being approximately $94 \%$ and $98 \%$ of the associated parameter estimates for Temp and PAR*Temp, respectively suggests minimal support for the role of these two parameters in driving the temporal pattern of GPP observed. The depth parameter exhibited a large standard error such that the parameter estimate $85 \%$ confidence interval overlapped zero indicating little support for depth as a driver of GPP.

Evaluation of a priori CR models indicated that CR Model 8 (Table 4.4), which contained GPP, Temp and Depth as environmental drivers, explained 27\% of CR variation and had an evidence weight of 0.53 . As predicted, GPP, Temp and Depth were all positively associated with $\mathrm{CR}$ (parameter estimates \pm SE: GPP $=1.209 \pm 0.159$, Temp $=1.803 \pm 0.260$, Depth $=0.203 \pm 0.102$ ). Three other models, Models 7, 15 and 16, were within 7 AICc units of Model 8. However, the global model, Model 16, was discarded because the addition of the GPP*Temp parameter resulted in a model that differed from Model 8 by greater than 4 AICc units suggesting this parameter is uninformative. Similarly, Model 15 was a more complex version of Model 7 where the addition of the 
GPP*Temp parameter did not result in an enhanced model. Model 7 was a simpler version of the best model, Model 8 , and had a weight of 0.33 but was 1 AICc unit less than the best model indicating that the addition of the Depth parameter to Model 8 improved our understanding of variation in CR.

The NDM a priori global model, Model 16, had strong support with a weight of 0.70 (Table 4.5), which was over four times greater than the next best model. PAR (3.24 $\pm 1.040)$, and Temp $(1.612 \pm 0.898)$ were positively correlated to NDM whereas Depth ($0.248 \pm 0.099)$ and PAR*Temp $(-2.348 \pm 0.796)$ were negatively associated. Model 16 had an adjusted $\mathrm{R}^{2}$ of 0.53 indicating that the majority of variation in NDM over the sampling period could be explained by the four included parameters. 


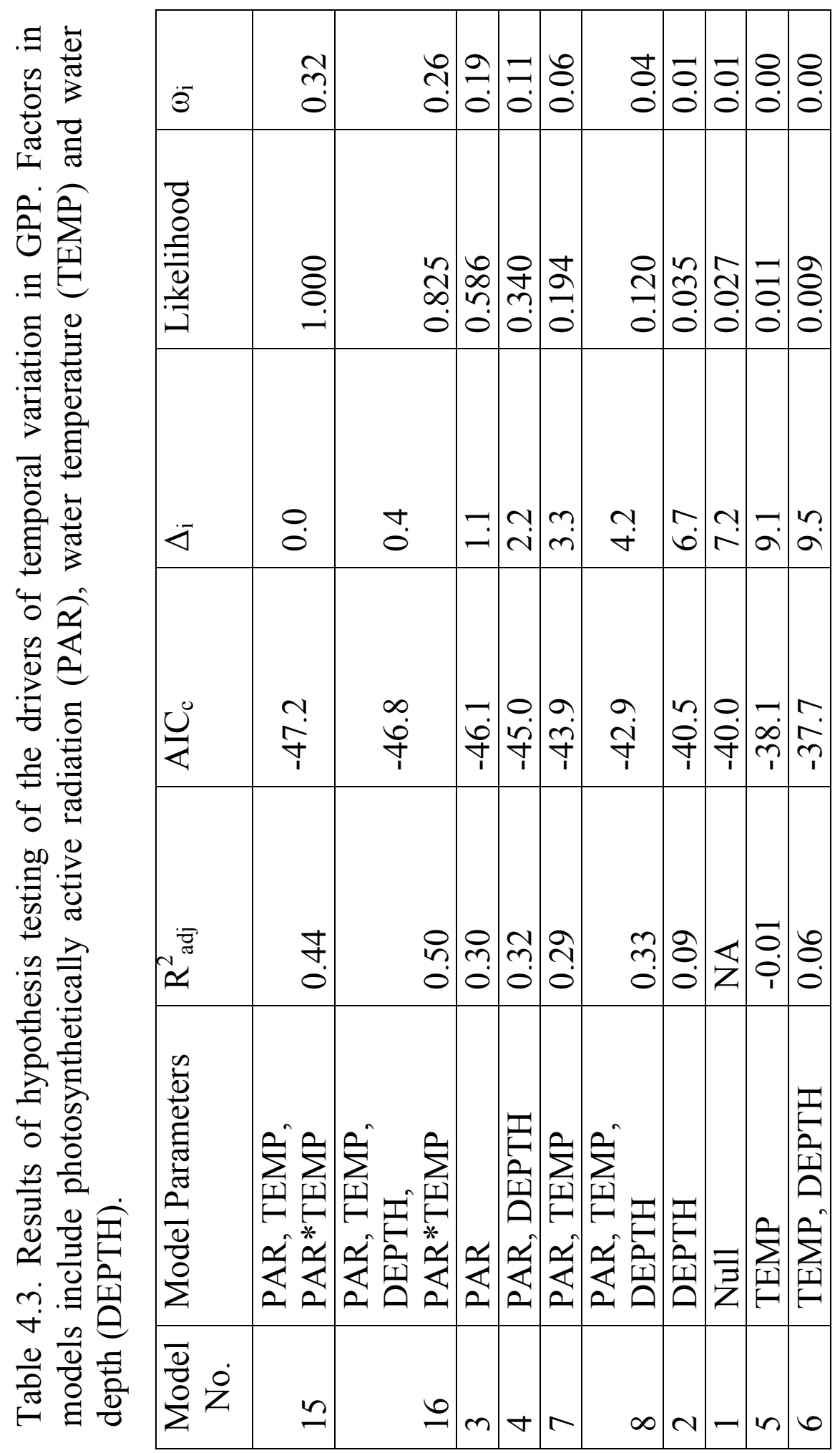




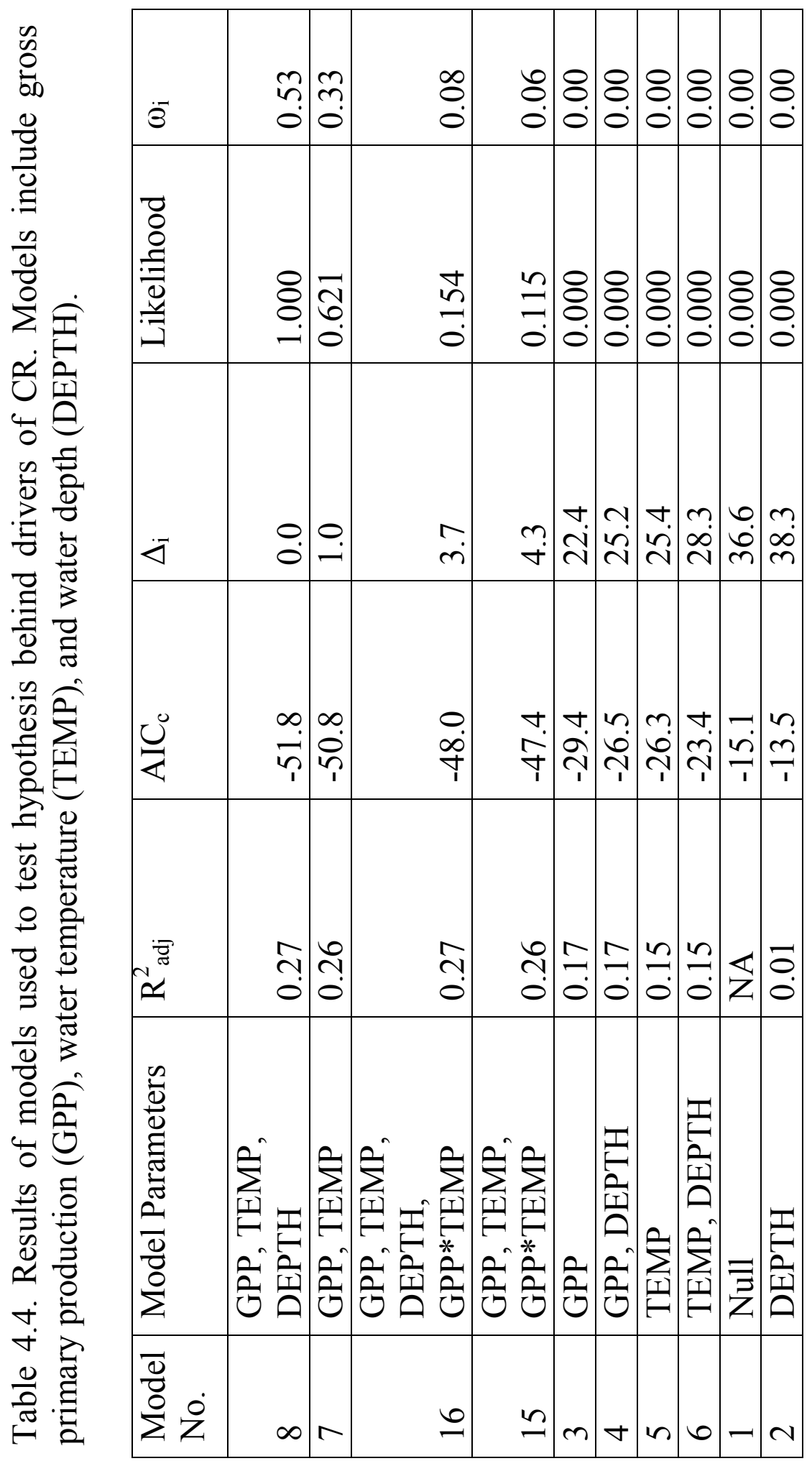




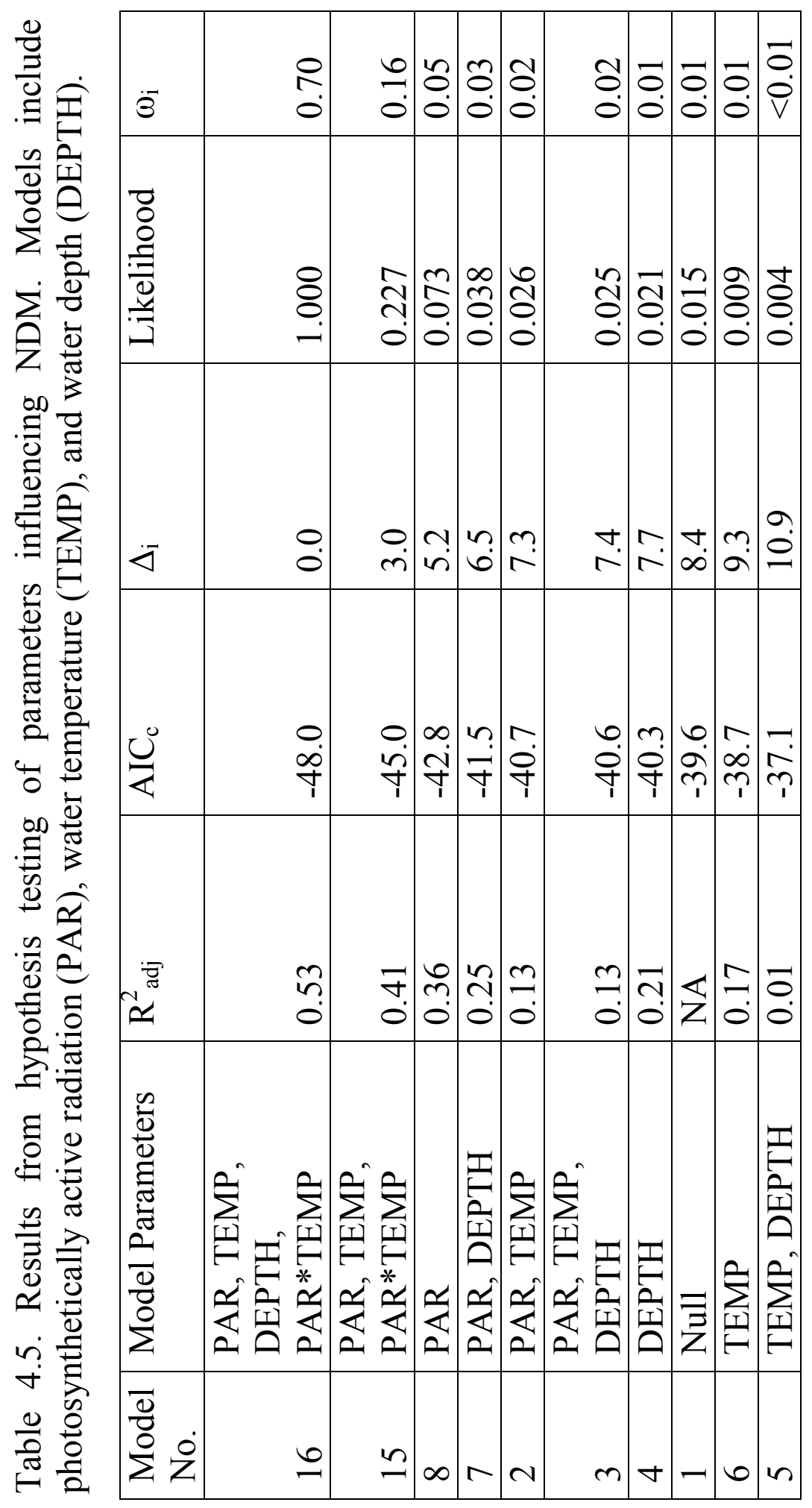




\subsection{Discussion}

Our assessment of benthic metabolism in the Saint John River suggests that spatial and temporal heterogeneity in this key ecosystem process is controlled by interactions between physical habitat characteristics and seasonally driven climatic conditions. Spatiotemporal patterns of metabolism are influenced by substrate type and flow regulation indicates that patterns of benthic metabolism in the Saint John River are consistent with observations from small streams.

\subsection{Comparison to Other Studies}

Rates of benthic metabolism measured during our study (median $=3.06 \mathrm{~g} \mathrm{O}_{2} \mathrm{~m}^{-2}$ $\mathrm{d}^{-1}$ ) ranged from 0.11 to $5.38 \mathrm{~g} \mathrm{O}_{2} \mathrm{~m}^{-2} \mathrm{~d}^{-1}$ for GPP, (median $=0.78 \mathrm{~g} \mathrm{O}_{2} \mathrm{~m}^{-2} \mathrm{~d}^{-1}$ ) 0.16 to $1.28 \mathrm{~g} \mathrm{O}_{2} \mathrm{~m}^{-2} \mathrm{~d}^{-1}$ for $\mathrm{CR}$, and (median $=2.29 \mathrm{~g} \mathrm{O}_{2} \mathrm{~m}^{-2} \mathrm{~d}^{-1}$ ) -0.06 to $4.11 \mathrm{~g} \mathrm{O}_{2} \mathrm{~m}^{-2} \mathrm{~d}^{-1}$ for NDM. Other benthic chamber studies in large, temperate rivers have reported greater rates of CR, but rates of GPP within a similar range (Table 5.1). In particular, the mean GPP values we observed in the Saint John River were within $0.3 \mathrm{~g} \mathrm{O}_{2} \mathrm{~m}^{-2} \mathrm{~d}^{-1}$ of rates reported by Naiman (1983) for the Moisie River in eastern Quebec, Canada (Table 5.1). However, our CR rates were less than half of what has been reported by comparable studies (e.g., Naiman, 1983; Naimo \& Layzer, 1988; Rier \& King, 1996). Differences in CR could be linked to variations in methods between our study and previous studies. For example, Naiman (1983) included macrophytes and mosses in the chambers, whereas we excluded macrophytes. Likewise, other studies have used incubated sampling trays composed of fine substrate (Naimo \& Layzer, 1988), which could lead these other studies to capture additional respiration contributed by macrofauna and additional bacteria (Bunn et al., 1999; Clapcott \& Barmuta, 2010). Furthermore, our results indicate that the Saint John River is strongly autotrophic with average NDM values above $2\left(2.29 \mathrm{~g} \mathrm{O}_{2} \mathrm{~m}^{-2} \mathrm{~d}^{-1}\right)$, whereas other studies in temperate systems were only slightly autotrophic (Naiman, 1983; Rier \& King, 1996) or heterotrophic (Naimo \& Layzer, 1988) (Table 5.1). A methodological difference could also explain our larger NDM rates as Naiman (1983) assumed 1/4 of surface area on cobble substrate was photosynthetically available in their metabolism calculations, where we followed the guidance of Grace \& Imberger (2006) and assumed $1 / 2$ of cobble surface was photo-available. The discrepancy in 
photosynthetically available surface area could explain why our GPP rates are comparable to Naiman (1983) even though they included macrophytes in their benthic chambers. Autotrophy of the Saint John River and other large temperate rivers (Table 5.1) can likely be attributed to increasing PAR availability as river widening leads to open canopies (Vannote et al., 1980; Naiman, 1983). Mulholland et al. (2001) proposed that when net ecosystem production is controlled by PAR, rather than nutrient availability primary production measurements should exhibit greater variation than respiration. Thus, our results indicate PAR limitation is the dominant control of NDM in the Saint John River as variation in GPP $($ Median $=0.82)$ was over four times larger than $\mathrm{CR}($ Median $=$ $0.18)$.

Table 5.1. Measured rates of benthic metabolism in temperate North American rivers. Average $( \pm \mathrm{SD})$ are shown.

\begin{tabular}{llll}
\hline \hline Author & River & $\mathrm{GPP}\left(\mathrm{g} \mathrm{O}_{2} \mathrm{~m}^{-2} \mathrm{~d}^{-1}\right)$ & $\mathrm{CR}\left(\mathrm{g} \mathrm{O}_{2} \mathrm{~m}^{-2} \mathrm{~d}^{-1}\right)$ \\
\hline \hline This study & Saint John & $2.93(1.38)$ & $0.76(0.29)$ \\
& & & \\
Naiman, 1983 & Moisie & $\sim 3.16$ & $\sim 1.82$ \\
Naimo \& Layzer, 1988 & Tombigbee & $1.93(0.62)$ & $4.32(0.84)$ \\
Rier \& King, 1996 & North Chippewa & 3.38 & $1.46^{1}$
\end{tabular}

\subsection{River Substrate}

Substrate variation contributed to spatial heterogeneity of GPP, but only during the earlier summer months (i.e., June and July) when sand substrates had lower rates of production than cobble. Differing rates of GPP between substrate types is consistent with a study of the Chippewa River by Rier \& King (1996), who also observed greater rates of production on cobble substrate compared to sand during the summer months. However, in contrast to Rier \& King (1996), our results also indicated temporal variation in the effect

\footnotetext{
${ }^{1}$ Values are approximated from figures in Naiman, 1983 study. No standard deviations were presented in the text.
} 
of substrate, as we observed no difference in GPP between substrate types in August. The increased production in sand substrate during August may be attributed to a differential increase in bed PAR between sites as summer progressed. During the August sampling period, nearly three times as much PAR reached the bed at the sand site compared to the cobble site and likely prompted greater biomass growth and accumulation. This hypothesis is supported by our observation of between substrate differences in chlorophyll-a concentrations. The increase in chlorophyll-a provides an indication that PAR and biomass development led the sites to become more similar despite substrate differences. Differences in stability between substrates may also have contributed to between site similarities later in summer as the threshold of shear stress to move cobble substrate in the riverbed is over one magnitude larger than sand (Miller et al., 1977). Daily water fluctuations were approximately twice as large in June and July (0.4-0.5 m) compared to August (0.2 m) (Environment and Climate Change Canada, 2017), likely decreasing bed movement leading up to the August sampling period allowing for greater algal accumulation in sand substrate compared to earlier in the summer (sensu Tett et al., 1978). Although our findings were consistent with previous large river studies, past studies on small streams by Clapcott \& Barmuta (2010) and Fellows et al. (2006) found fine substrate had greater rates of GPP than cobble. However, results from both large rivers and small streams indicate that substrate type consistently influences rates of metabolism although the direction of the relationship may vary depending on the size of the river.

Contrary to our hypothesis, sand substrate did not have significantly greater rates of CR throughout the summer. Cobble CR was greater than sand in June but no statistical difference was detected in July or August. Our results differ from a study by Fellows et al., (2006), who found sand substrate to have significantly greater rates of respiration, with additional respiration attributed to the benthic chambers enclosing the entire microbial community. Conversely, cobble respiration measurements would instead be limited to the microbial community growing on the surface of the cobble inserted into the chamber (Fellows et al., 2006). However, in the larger Chippewa River, Rier \& King (1996) found higher respiration at cobble substrate sites in all summer months and 
suggested that unstable conditions in sand may not be suitable for primary producers, or heterotrophs (i.e., bacteria) and therefore limited respiration rates in the fine substrate habitats. Low CR rates at our sand site suggest disturbance from high water levels and flow fluctuations following spring melt may have delayed establishment of autotrophs and heterotrophs resulting in the noted differences between substrate types in June. Seasonal instability of substrate is supported by findings of O'Connor et al. (2012), who observed that sand substrate was mobilized during small increases in discharge (from 3.1 to $3.2 \mathrm{~m} / \mathrm{s}$ ) in the South Fork Iowa River. Moreover, Gerull et al. (2012) found that metabolism rates can be reduced by increases in stream flow even when disturbance is limited to the top $1 \mathrm{~cm}$ of sand in a riverbed. As summer progressed, patches of macrophytes emerged in the Saint John River, adding hydraulic stability to the sand site and potentially allowing algae and microbial communities to accumulate and induce increased respiration. The only negative NDM results in our entire study were observed during June and July at our sand substrate sites suggesting slightly heterotrophic conditions in the early summer when there was a greater frequency of high discharge with associated bed disturbance (Environment and Climate Change Canada, 2017). Production during these months was less than $0.2 \mathrm{~g} \mathrm{O}_{2} \mathrm{~m}^{-2} \mathrm{~d}^{-1}$ and GPP was negligible, likely as a result of low PAR $\left(0.29-27.3 \mathrm{~mol} \mathrm{~m}^{-2} \mathrm{~d}^{-1}\right)$ in these months. Conversely, cobble NDM increased in each consecutive month, indicating sites with stable substrate became more autotrophic as the summer progressed. Seasonal changes in NDM at the cobble site were likely associated with PAR as light also increased in consecutive months.

\subsection{Channel Location}

Our assessment comparing benthic metabolism in the main and side channel areas of the Saint John River revealed a significant difference of CR in July, with the side channel having approximately $50 \%$ greater CR than the main channel. However, our results indicated that GPP was not different between main and side channels sites in the Saint John River; therefore there is little evidence of production driving differences in respiration rates between our sites. Our environmental parameters (PAR, temperature, nutrients, etc.), albeit based on limited sampling, also did not appear to be different 
enough to cause a measureable difference in CR. Although there was a statistical difference in CR between channel locations during July, rates of respiration were small and only differed by $0.44 \mathrm{~g} \mathrm{O}_{2} \mathrm{~m}^{-2} \mathrm{~d}^{-1}$, an amount that may not be biologically relevant considering inherent variation between individual sampling locations within a site. Similarities between channel locations may have been caused by the high connectivity between the adjacent main and off-channel habitats in Saint John River throughout the summer. The high connectivity of flow could be preventing the substantive differences in key environmental drivers such as nutrient availability, light penetration and bed disturbance, required to generate a difference between channel locations. Contrary to our results, Houser et al. (2015) generally found greater rates of production and respiration at their backwater sites in their temporal evaluation of ecosystem metabolism in the main channel and backwaters of the Upper Mississippi River. For instance, in the second year of their study, both production and respiration were significantly greater at all backwater sites compared to main channel (Houser et al., 2015). However, the main and side channel locations used in our study exhibited less variation in key habitat variables such as velocity, substrate and presence of macrophytes than did the sites in the Houser et al. (2015) study. Sampling of sites with greater hydrogeomorphic range in the Saint John River may thus be needed to fully understand benthic metabolism in side channel areas.

\subsection{Flow Regulation}

Our results from the comparison of the regulated river reaches support our hypothesis of temporal differences in benthic metabolism; with flow regulation found to be most influential following spring rain events in June. As predicted, there were no significant differences between sites in June, likely attributed to capacity constraints of each reservoir, which are subject to seasonal flood flows from high spring precipitation. When reservoirs reach capacity, most dams function as run-of-the-river generating stations (Majumder \& Ghosh, 2013), and we speculate this is what happened in the Saint

John River under these higher flow conditions prior to water levels stabilizing in July. Previous studies of the effects of regulation on benthic metabolism indicate GPP increases downstream of a dam (Munn \& Brusven, 2004; Chester \& Norris, 2006). Our 
findings are consistent with past studies as the more intensely regulated medium-head downstream reach produced greater GPP rates in both July and August. A combination of factors are likely responsible for GPP differences between sites. First, as the upstream low-head Beechwood dam has a very small storage capacity it acts as a run-of-the-river dam in all but the driest parts of the season. However, the medium-head Mactaquac Generating Station has an extensive reservoir and exhibits greater control over water flow, possibly generating a difference in the amount of downstream disturbance between the two study reaches. Although we did not directly measure disturbance events, changes in stage coupled with concurrent changes in biomass provide evidence of the impacts of disturbance. For example, during our July sampling period, maximum stage upstream was over twice as great as downstream, suggesting greater potential for disturbance. Furthermore downstream chlorophyll-a and AFDM were over eight times greater than the upstream and could have caused the observed differences in GPP. However, chlorophylla concentrations were less than $0.07 \mu \mathrm{g} / \mathrm{cm}^{2}$ apart between sites in August, suggesting GPP differences between sites was not associated with biomass. Above average rainfall in August could explain why chlorophyll-a and AFDM measurements became more similar despite differences in flow regulation, as water stage in the medium-head reach increased nearly $1 \mathrm{~m}$ in the days leading up to our August sampling and may have caused bed scouring and removed accumulated algae from the substrate. Furthermore, differences in GPP during August can be attributed to over three times greater bed PAR in the mediumhead reach, potentially promoting production at this site, as light is a key driver of GPP (Mulholland et al., 2001; Izaguirre et al., 2008; Bernot et al., 2010).

Previous research has suggested flow regulation can increase $\mathrm{CR}$ rates immediately downstream of a dam (Munn \& Brusven, 2004). Our findings support this claim as July CR in the medium-head reach was greater than all other measurements. As previously described, both June and August had high precipitation rates seemingly changing flow regulation to run-of-the-river, whereas in July hydropeaking was more consistent. Comparable to our results, Munn \& Brusven (2004) found seasonality to be important for CR rates; however, their study covered a greater period of time with lowest $\mathrm{CR}$ occurring in spring and greatest respiration rates occurring in the summer and fall. 


\subsection{Temporal Variation}

Studies examining metabolism in large rivers have found it to be temporally variable (Naiman 1983; Dodds et al., 2013). Temporal patterns of benthic metabolism in the Saint John River over the summer were similar to Naiman (1983) who used benthic chambers in the nearby Moise River in Quebec. Specifically, we also found GPP to reach a maximum rate in July with rates exceeding $4 \mathrm{~g} \mathrm{O}_{2} \mathrm{~m}^{-2} \mathrm{~d}^{-1}$. Although there were no significant differences among weeks, there was a quadratic temporal-trend to GPP, as it peaked in mid-summer, likely due to the 2 to 3 fold increase in PAR in weeks 4 and 5 . Indeed, regression analyses findings suggest that variation in summer rates of GPP in the Saint John River are primarily driven by light availability. The importance of PAR to GPP is consistent with many studies of stream metabolism in small streams such as Sumner et al. (1979), who also found peak GPP coincided with peak PAR, although their study took place in a forested stream and production was greatest in spring before leaf emergence. Another temporal study, by Minshall et al. (1992), in the $8^{\text {th }}$ order Salmon River Basin, Idaho, found benthic GPP peaked in summer, with lower rates in both spring and autumn. If our study had been extended from spring through fall then we would likely have seen similar results in the Saint John River. Conversely, production at another $8^{\text {th }}$ order river, Slate Creek, increased progressively from spring through fall but less than $21 \%$ of GPP could be attributed to the benthic community, which was attributed to reduced light availability to benthic areas at deeper water depths (Minshall et al., 1992). The lack of association between temporal variation in GPP and hydropeaking in the Saint John is not, however, consistent with previous literature, which has found reduction of disturbances from flow regulation to increase primary production (Aristi et al., 2014). This could be because the daily flow releases in the Saint John River were not large enough in most cases to scour periphyton from the substrate to facilitate new growth. However, we did not measure disturbance gradients and further investigation would be needed to support this hypothesis. 
The finding that temporal variation in CR was associated with GPP, hydropeaking and temperature is consistent with previous studies (Bott et al., 1985; Fellows et al., 2006; Bernot et al., 2010). For example, CR rates are expected to be positively correlated to GPP (Fellows et al., 2006), with measured respiration contributed by periphyton on cobble substrate (Bunn et al., 1999). Our results provide evidence of this relationship as both GPP and CR measurements were lowest in week 1 and greatest in week 5. Due to the design of our study with substrate enclosed in chambers, impacts of hydropeaking were likely established on substrate in the days leading up to sampling. It is also likely these daily changes in water depth were indirectly linked to GPP through the effect water depth has on PAR. Our GPP model did not include hydropeaking, but PAR was the most important variable and we can speculate water depth change from river regulation altered turbidity and light penetration throughout the day. Although, our speculation of water depth influencing GPP could be coincidentally related to weather related factors, such as cloud cover, which can reduce light reaching the benthic community (Dodds et al., 2013). Indeed, there is evidence of PAR restriction from cloud cover in our results, as CR was less variable within individual weeks than GPP. Our finding of an association between temperature and $\mathrm{CR}$ is also consistent with other studies that found strong support of this relationship (Bott et al., 1985; Uehlinger et al, 2000). However, there are conflicting results from a study by Mulholland et al. (2001) where no statistical significance was found between respiration rates and temperature.

NDM was associated with all environmental parameters used in our model, (positively related: PAR, water temperature; negatively related: hydropeaking, PAR*Temp) explaining over half of the variation, which is not surprising as all four parameters were included in the best models for either GPP or CR. However, the positive relationship with temperature was unanticipated based on the findings of Clapcott \& Barmuta (2010) where temperature was negatively associated with cobble NDM, contradicting our results. Similarly, in our model results temperature was deemed uninformative for GPP but positively associated with CR. Our rates of NDM are driven by GPP, as production was about four times larger than CR in each week. 


\subsection{Implication and Applications}

Understanding river metabolism is important for informing management of these ecosystems, because many variables influence production and respiration, with metabolism providing an important functional indicator of stream health (Bunn et al., 1999). It is also useful to know if prior metabolic patterns in small streams persist in larger rivers because it means we can apply our existing knowledge to understudied large rivers, which are logistically more difficult to study. Moreover, our study has contributed to the theoretical knowledge of large rivers as relationships between substrate types and temporal drivers of GPP were upheld, meaning we may be able to apply basic conceptual models of small streams to large rivers.

Results of our study can also form the foundation for developing benthic metabolism as an indicator for ecosystem monitoring in the Saint John River. First, we have generated baseline data of benthic metabolism indicating the current state of the Saint John River ecosystem. Second, our study has provided key insights regarding developing benthic metabolism as a tool for monitoring in the Saint John River by establishing patterns of heterogeneity within the river. Indeed, because our study found that, rates of benthic metabolism varied both spatially and temporally we recommend identifying one area indicative of dominant river conditions (e.g., main channel cobble site used in all parts of our study) to monitor long-term changes in benthic metabolism and water quality. Once a trend site, or sites, is selected monitoring will have to be regulated by consistently sampling at the same sites at the same time of the year.

The development of a long-term monitoring program will allow researchers to track changes of benthic metabolism rates in the Saint John River ecosystem, especially in regards to the impacts of increasing temperature regimes associated with climate change that could impact the Saint John River. Acuna et al. (2008) studied the relationship between respiration and water temperature, finding a $20 \%$ increase in respiration with a $2.5^{\circ} \mathrm{C}$ increase in water temperature. Our results also indicate temperature is a driver of $\mathrm{CR}$ and this evidence suggests a rise in water temperature could cause a shift in the river from autotrophy to heterotrophy as respiration increases. 
Considering the findings of this study, CR could potentially be used as an indicator of environmental stress as water temperature warms. Our results also provide insight into the likely change in the river in the wake of rising temperatures; however, strategic management of the Mactaquac Generating Station could potentially be used to counteract water warming, and thus changes in benthic respiration rates. Multiple studies (see Preece \& Jones, 2002; Null et al., 2013) have found water released from deep reservoirs is relatively cooler during the summer when compared to unregulated conditions; meaning climate change could be mitigated with released of cooler water.

\subsection{Study Limitations and Further Research}

This thesis has demonstrated spatio-temporal patterns of benthic metabolism within the Saint John River by identifying differences in rates of metabolism between substrate types, channel locations, and flow regulation management over the course of a summer season. However, this was a preliminary investigation and there were some unavoidable limitations. First, the research design relied on benthic chambers, which have common limitations outlined by Grace \& Imberger (2006). Specifically, benthic chambers have been reported to underestimate rates of $\mathrm{CR}$, which could have contributed to high NDM rates in our study. Second, benthic chambers provide scaling problems as they can only estimate rates of metabolism for the enclosed habitat. Thus, estimates of wholeecosystem metabolism from chambers exclude other habitat components such as macrophytes and inverebrates. Thus, although our hypotheses pertained to benthic metabolism of habitat patches within the river, it is difficult to scale these findings to the river reach or segment scales. Third, due to the physical constraints of our benthic chambers, we focused on primary producers directly attached to substrate to estimate metabolism. We understand producers such as phytoplankton and submerged macrophytes that may be important contributors to stream metabolism were excluded. However, as our goal was to focus on benthic metabolism and a small suite of environmental drivers acting primarily at the patch or sub-habitat scale we elected to control as much variation as possible in our comparisons by omitting non-benthic ecological components. 
In order to better evaluate the health of riverine systems, indicators such as benthic metabolism should be further investigated for an increased understanding of controls and inherent patterns of variability. Future research in the Saint John River may benefit from investigating annual patterns of benthic metabolism in the river associated with emergence, growth and die-off of primary producers by expanding sampling further into spring and autumn months. Naiman (1983) found seasonal variation of benthic metabolism in the Moisie River over an annual study, and extending the temporal scope of our study would provide more information about how metabolism changes seasonally. In addition, as our study focused on benthic metabolism and excluded other primary producers such as phytoplankton and submerged macrophytes, studies undertaking a more ecologically complete assessment of metabolism could provide important insight into rates of metabolism in the Saint John River. For instance, a study of the Murray River in Australia compared phytoplankton and whole system metabolism and found no significant difference between the two, suggesting plankton were an important contributor to metabolism within the river (Oliver \& Merrick, 2006). Likewise, other studies have investigated macrophyte metabolism finding this ecological compartment can also make a significant contribution to stream metabolism (Uehlinger, 1993; Kaenel, Buehrer \& Uehlinger, 2000). Investigating these additional primary producers could produce a whole-stream metabolism estimate for the Saint John River, to enhance comparison with studies from other temperate rivers, such as the Moise River (Naiman, 1983). Finally, as our study found minimal impact of the dam, a longitudinal study in closer proximity to Mactaquac Generating Station could provide knowledge about how the impact of flow regulation dissipates downstream. A study by Munn \& Brusven (2004) investigated the change of benthic metabolism between sites at different locations downstream of the Dworshak Dam and found the impacts of flow regulation were only measurable immediately downstream of the dam. Setting up multiple sites increasingly downstream of the dam would allow us to measure longitudinal trends of metabolism downstream. Future research should focus on the relationships between metabolism and environmental variables and may need to be replicated in other large river systems in order to build our fundamental knowledge about ecosystem functioning in these complex systems. 


\subsection{Conclusions}

Spatial and temporal heterogeneity of benthic metabolism in the Saint John River is controlled by the interaction of habitat type and season. Stable cobble substrate had greater production than sand substrate early in the summer when river flows were high. More intense flow regulation provided greater rates of GPP, CR and NDM, although no differences were found when the reservoirs reached full capacity. Similar to small streams, our findings indicate PAR and water temperature are important environmental drivers of metabolism in a large regulated river. Results from this research indicate that benthic metabolism varies both spatially and temporally in large rivers and due to heterogeneity within large rivers, an area representing the dominant river conditions should be used for biomonitoring. As well, future research should investigate the contribution of other primary producers (i.e. macrophytes, phytoplankton) and determine their contribution to stream metabolism to gain a better understanding of whole ecosystem metabolism. 


\subsection{References}

Acuña, V., Wolf, A., Uehlinger, U., \& Tockner, K. (2008). Temperature dependence of stream benthic respiration in an Alpine river network under global warming. Freshwater Biology, 53(10), 2076-2088.

Acuña, V., Vilches, C., \& Giorgi, A. (2010). As productive and slow as a stream can bethe metabolism of a Pampean stream. Journal of the North American Benthological Society, 30(1), 71-83.

Akaike, H. 1973. Information theory as an extension of the maximum likelihood principle. Pages 267-281 in B. N. Petroy and F. Csaki (editors). Second International Symposium on Information Theory. Akademiai Kiado, Budapest.

Anderson, D. R. 2008. Model Based Inference in the Life Sciences: A Primer on Evidence. Springer, New York.

Aristi, I., Arroita, M., Larrañaga, A., Ponsatí, L., Sabater, S., Schiller, D., Elosegi, A., \& Acuña, V. (2014). Flow regulation by dams affects ecosystem metabolism in Mediterranean rivers. Freshwater Biology, 59(9), 1816-1829.

Arnold, T. W. 2010. Uninformative parameters and model selection using Akaike's information criterion. Journal of Wildlife Management 74:1175-1178.

Bartoń, K. (2016). MuMIn: Multi-Model Inference. R package version 1.15.6. https://CRAN.R-project.org/package=MuMIn

Bernot, M.J., Sobota, D.J., Hall R.O. et al. (2010). Inter-regional comparison of land-use effects on stream metabolism. Freshwater Biology. 55(9): 1874-1890.

Brismar, A. (2002). River systems as providers of goods and services: a basis for comparing desired and undesired effects of large dam projects. Environmental Management, 29(5), 598-609.

Bott, T. L., Brock, J. T., Dunn, C. S., Naiman, R. J., Ovink, R. W., \& Petersen, R. C. (1985). Benthic community metabolism in four temperate stream systems: an inter-biome comparison and evaluation of the river continuum concept. Hydrobiologia, 123(1), 3-45.

Bunn, S. E., Davies, P. M., \& Mosisch, T. D. (1999). Ecosystem measures of river health and their response to riparian and catchment degradation. Freshwater biology, 41(2), 333345.

Burnham K. P., and D. R. Anderson. 2002. Model Selection and Multimodel Inference: A Practical Information-Theoretic Approach. $2^{\text {nd }}$ edition. Springer, New York. 
Cardinale, B. J., Palmer, M. A., Swan, C. M., Brooks, S., \& Poff, N. L. (2002). The influence of substrate heterogeneity on biofilm metabolism in a stream ecosystem. Ecology, 83(2), 412-422.

Chester, H., \& Norris, R. (2006). Dams and flow in the Cotter River, Australia: effects on instream trophic structure and benthic metabolism. Hydrobiologia, 572(1), 275-286.

Clapcott, J. E., \& Barmuta, L. A. (2010). Metabolic patch dynamics in small headwater streams: exploring spatial and temporal variability in benthic processes. Freshwater Biology, 55(4), 806-824.

Cunjak, R.A., and Newbury, R.W. 2005. Atlantic coast rivers of Canada. In Rivers of North America. Edited by A.C. Benke and C.E. Cushing. Elsevier Inc. (Academic Press), San Diego, CA. pp. 939-980.

Curry, R.A., and Munkittrick, K.R. 2005. Fish assemblage structure in relation to multiple stressors along the Saint John River, New Brunswick, Canada. Amer. Fish. Soc. Symp. 45: 505-521.

Dodds, W. K., Veach, A. M., Ruffing, C. M., Larson, D. M., Fischer, J. L., \& Costigan, K. H. (2013). Abiotic controls and temporal variability of river metabolism: multiyear analyses of Mississippi and Chattahoochee River data.

Environment and Climate Change Canada. (2017, July 13). Retrieved August 10, 2017, from https://wateroffice.ec.gc.ca/report/real_time_e.html?stn=01AK003

Fellows, C. S., Clapcott, J. E., Udy, J. W., Bunn, S. E., Harch, B. D., Smith, M. J., \& Davies, P. M. (2006). Benthic metabolism as an indicator of stream ecosystem health. Hydrobiologia, 572(1), 71-87.

Gerull, L., Frossard, A., Gessner, M. O., \& Mutz, M. (2012). Effects of shallow and deep sediment disturbance on whole-stream metabolism in experimental sand-bed flumes. Hydrobiologia, 683(1), 297-310.

Grace, M. R., \& Imberger, S. J. (2006). Stream metabolism: performing and interpreting measurements. Water Studies Centre Monash University, Murray Darling Basin Commission and New South Wales Department of Environment and Climate Change, 204.

Graf, W. L. (2006). Downstream hydrologic and geomorphic effects of large dams on American rivers. Geomorphology, 79(3), 336-360. 
Grueber, C. E., Nakagawa, S., Laws, R. J., \& Jamieson, I. G. (2011). Multimodel inference in ecology and evolution: challenges and solutions. Journal of evolutionary biology, 24(4), 699-711.

Houser, J. N., Bartsch, L. A., Richardson, W. B., Rogala, J. T., \& Sullivan, J. F. (2015). Ecosystem metabolism and nutrient dynamics in the main channel and backwaters of the Upper Mississippi River. Freshwater biology, 60(9), 1863-1879.

Izagirre, O., Agirre, U., Bermejo, M., Pozo, J., \& Elosegi, A. (2008). Environmental controls of whole-stream metabolism identified from continuous monitoring of Basque streams. Journal of the North American Benthological Society, 27(2), 252-268.

Kaenel, B. R., Buehrer, H., \& Uehlinger, U. (2000). Effects of aquatic plant management on stream metabolism and oxygen balance in streams. Freshwater Biology, 45(1), 85-95.

Karr, J. R., \& Chu, E. W. (2000). Introduction: Sustaining living rivers (pp. 1-14). Springer Netherlands.

Kendrick, M. R., \& Huryn, A. D. (2015). Discharge, legacy effects and nutrient availability as determinants of temporal patterns in biofilm metabolism and accrual in an arctic river. Freshwater biology, 60(11), 2323-2336.

Li, H., Li, Z., Li, Z., Yu, J., \& Liu, B. (2015). Evaluation of ecosystem services: A case study in the middle reach of the Heihe River Basin, Northwest China. Physics and Chemistry of the Earth, Parts $A / B / C, 89,40-45$.

Ligon, F. K., Dietrich, W. E., \& Trush, W. J. (1995). Downstream ecological effects of dams. BioScience, 45(3), 183-192.

Majumder, M., \& Ghosh, S. (2013). Decision making algorithms for hydro-power plant location. Springer.

Millennium Ecosystem Assessment, (2005). Fresh water. Ecosystems and human wellbeing: current state and trends Findings of the condition and trends working group.

Miller, M. C., McCave, I. N., \& Komar, P. (1977). Threshold of sediment motion under unidirectional currents. Sedimentology, 24(4), 507-527.

Minshall, G. W., Petersen, R. C., Bott, T. L., Cushing, C. E., Cummins, K. W., Vannote, R. L., \& Sedell, J. R. (1992). Stream ecosystem dynamics of the Salmon River, Idaho: an 8th-order system. Journal of the North American Benthological Society, 11(2), 111-137.

Munn, M. D., \& Brusven, M. A. (2004). The influence of Dworshak Dam on epilithic community metabolism in the Clearwater River, USA. Hydrobiologia, 513(1-3), 121-127.

Mulholland, P.J., Fellows, C.S., Tank, J.L., et al. (2001). Inter-biome comparison of factors controlling stream metabolism. Freshwater Biology. 46(11): 1503-1517 
Naiman, R. J., \& Sedell, J. R. (1980). Relationships between metabolic parameters and stream order in Oregon. Canadian Journal of Fisheries and Aquatic Sciences, 37(5), 834847.

Naiman, R. J. (1983). The annual pattern and spatial distribution of aquatic oxygen metabolism in boreal forest watersheds. Ecological monographs, 53(1), 73-94.

Naimo, T. J., Layzer, J. B., \& Miller, A. C. (1988). Benthic community metabolism in two northern Mississippi streams. Journal of Freshwater Ecology, 4(4), 503-515.

Nilsson, C., Reidy, C. A., Dynesius, M., \& Revenga, C. (2005). Fragmentation and flow regulation of the world's large river systems. Science, 308(5720), 405-408.

Null, S. E., Ligare, S. T., \& Viers, J. H. (2013). A method to consider whether dams mitigate climate change effects on stream temperatures. JAWRA Journal of the American Water Resources Association, 49(6), 1456-1472.

O'Connor, B. L., Harvey, J. W., \& McPhillips, L. E. (2012). Thresholds of flow-induced bed disturbances and their effects on stream metabolism in an agricultural river. Water Resources Research, 48(8).

Oliver, R. L., \& Merrick, C. J. (2006). Partitioning of river metabolism identifies phytoplankton as a major contributor in the regulated Murray River (Australia). Freshwater Biology, 51(6), 1131-1148.

Poff, N. L., Olden, J. D., Merritt, D. M., \& Pepin, D. M. (2007). Homogenization of regional river dynamics by dams and global biodiversity implications. Proceedings of the National Academy of Sciences, 104(14), 5732-5737.

Preece, R. M., \& Jones, H. A. (2002). The effect of Keepit Dam on the temperature regime of the Namoi River, Australia. River Research and Applications, 18(4), 397-414.

Preiner, S., Drozdowski, I., Schagerl, M., Schiemer, F., \& Hein, T. (2008). The significance of side-arm connectivity for carbon dynamics of the River Danube, Austria. Freshwater Biology, 53(2), 238-252.

Reynoldson, T.B., Logan, C., Pascoe, T., \& Thompson, S.P. (2007). CABIN Canadian Aquatic Biomonitoring Network invertebrate biomonitoring field and laboratory manual. Canada National Water Research Institute, Environment Canada Retrieved June 18 2015, from http://cabin.cciw.ca/Application/Downloads/cabin_protocol.doc.

Rier, S. T., \& King, D. K. (1996). Effects of inorganic sedimentation and riparian clearing on benthic community metabolism in an agriculturally-disturbed stream. Hydrobiologia, 339(1), 111-121. 
Roberts, B. J., Mulholland, P. J., \& Hill, W. R. (2007). Multiple scales of temporal variability in ecosystem metabolism rates: results from 2 years of continuous monitoring in a forested headwater stream. Ecosystems, 10(4), 588-606.

Rosenfeld, J., \& Roff, J. C. (1991). Primary production and potential availability of autochthonous carbon in southern Ontario streams. Hydrobiologia, 224(2), 99-109.

Sobotka, M. J., \& Phelps, Q. E. (2017). A Comparison of Main and Side Channel Physical and Water Quality Metrics and Habitat Complexity in the Middle Mississippi River. River Research and Applications, 33(6), 879-888.

Sumner, W. T., \& Fisher, S. G. (1979). Periphyton production in Fort River, Massachusetts. Freshwater Biology, 9(3), 205-212.

Systat Software Inc. 2015. Systat: Statistical and Graphing Software (Version 13). San Jose, California.

Tank, J. L., Rosi-Marshall, E. J., Baker, M. A., \& Hall, R. O. (2008). Are rivers just big streams? A pulse method to quantify nitrogen demand in a large river. Ecology, 89(10), 2935-2945.

Tett, P., Gallegos, C., Kelly, M. G., Hornberger, G. M., \& Cosby, B. J. (1978). Relationships among substrate, flow, and benthic microalgal pigment density in the Mechums River, Virginia. Limnology and Oceanography, 23(4), 785-797.

Uehlinger, U. (1993). Primary production and respiration in the outlet of an eutrophic lake (River Glatt, Switzerland). Archiv für Hydrobiologie, 128(1), 39-55.

Uehlinger, U., König, C., \& Reichert, P. (2000). Variability of photosynthesis-irradiance curves and ecosystem respiration in a small river. Freshwater Biology, 44(3), 493-507.

Vannote, R. L., Minshall, G. W., Cummins, K. W., Sedell, J. R., \& Cushing, C. E. (1980). The river continuum concept. Canadian journal of fisheries and aquatic sciences, 37(1), 130-137.

Velasco, J., Millan, A., Vidal-Abarca, M. R., Suarez, M. L., Guerrero, C., \& Ortega, M. (2003). Macrophytic, epipelic and epilithic primary production in a semiarid Mediterranean stream. Freshwater Biology, 48(8), 1408-1420.

Ward, J. V., \& Stanford, J. A. (1983). The serial discontinuity concept of lotic ecosystems. Dynamics of lotic ecosystems, 10, 29-42.

Ward, J. V., Tockner, K., \& Schiemer, F. (1999). Biodiversity of floodplain river ecosystems: ecotones and connectivity. Regulated rivers: research \& management, 15(1), 125-139. 
Ward, J. V., \& Tockner, K. (2001). Biodiversity: towards a unifying theme for river ecology. Freshwater Biology, 46(6), 807-820.

Young, R. G., Townsend, C. R., \& Matthaei, C. (2004). Functional indicators of river ecosystem health - an interim guide for use in New Zealand. Cawthron Rep, 870, 495523. 


\section{Appendix 1}

\begin{tabular}{|c|c|c|c|c|}
\hline Site & Location & Substrate & $\begin{array}{l}\text { Average Flow } \\
\text { Velocity }(\mathrm{m} / \mathrm{s})\end{array}$ & $\begin{array}{l}\text { Average } \\
\text { Chamber Depth } \\
\text { Underwater } \\
\text { (m) }\end{array}$ \\
\hline $\begin{array}{l}\text { Main channel } \\
\text { cobble, } \\
\text { medium-head } \\
\text { regulation }\end{array}$ & $\begin{array}{l}\text { N 455' } 18^{\prime \prime} \\
\text { W 664' } 1 "\end{array}$ & Cobble & 0.05 & 0.5 \\
\hline $\begin{array}{l}\text { Main channel } \\
\text { sand }\end{array}$ & 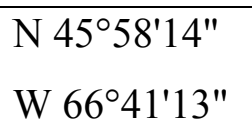 & Sand & 0.06 & 0.6 \\
\hline Side channel & 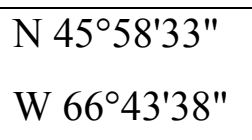 & Cobble & 0.07 & 0.3 \\
\hline $\begin{array}{l}\text { Low-head } \\
\text { regulation }\end{array}$ & $\begin{array}{l}\text { N } 4620^{\prime} 49^{\prime \prime} \\
\text { W } 6733^{\prime} 27^{\prime \prime \prime}\end{array}$ & Cobble & 0.15 & 0.4 \\
\hline
\end{tabular}

Location and characteristics of sites used in Assessments 1-4 in the Saint John River. All measurements were taken during the summer of 2016. 


\section{Appendix 2}

\begin{tabular}{|c|c|c|c|c|}
\hline Parameter & Abbreviation & $\begin{array}{l}\text { Detection } \\
\text { Limit (ppb) }\end{array}$ & Method Name & Instrument \\
\hline Ammonia & NH3 & 3 & $\begin{array}{l}\text { Determination of Ammonia in } \\
\text { Surface and Wastewaters by } \\
\text { Flow Injection Analysis }\end{array}$ & $\begin{array}{l}\text { Lachat QuickChem QC8500 } \\
\text { FIA Automated Ion Analyzer }\end{array}$ \\
\hline $\begin{array}{l}\text { Nitrite } \quad+ \\
\text { Nitrate }\end{array}$ & $\mathrm{NO} 2+\mathrm{NO} 3$ & 2 & $\begin{array}{l}\text { Determination of Nitrate/Nitrite } \\
\text { in Surface and Wastewaters by } \\
\text { Flow Injection Analysis }\end{array}$ & $\begin{array}{l}\text { Lachat QuickChem QC8500 } \\
\text { FIA Automated Ion Analyzer }\end{array}$ \\
\hline Total Nitrogen & $\mathrm{TN}$ & 6 & $\begin{array}{l}\text { Automated Determination of } \\
\text { Total Nitrogen and Total } \\
\text { Dissolved Nitrogen by Flow } \\
\text { Injection Analysis }\end{array}$ & $\begin{array}{l}\text { Lachat QuickChem QC8500 } \\
\text { FIA Automated Ion Analyzer }\end{array}$ \\
\hline $\begin{array}{l}\text { Total Kjeldahl } \\
\text { Nitrogen }\end{array}$ & TKN & 6 & $\begin{array}{l}\text { Automated Determination of } \\
\text { Total Kjeldahl Nitrogen by } \\
\text { Flow Injection Analysis }\end{array}$ & $\begin{array}{l}\text { Lachat QuickChem QC8500 } \\
\text { FIA Automated Ion Analyzer }\end{array}$ \\
\hline $\begin{array}{l}\text { Soluble } \\
\text { Reactive } \\
\text { Phosphorus }\end{array}$ & SRP & 1 & $\begin{array}{l}\text { Automated Determination of } \\
\text { Soluble Reactive Phosphorus } \\
\text { (SRP) by Flow Injection } \\
\text { Analysis }\end{array}$ & $\begin{array}{l}\text { Lachat QuickChem QC8500 } \\
\text { FIA Automated Ion Analyzer }\end{array}$ \\
\hline $\begin{array}{l}\text { Total } \\
\text { Phosphorus }\end{array}$ & TP & 1 & $\begin{array}{l}\text { Determination of Total } \\
\text { Phosphorus and Total Dissolved } \\
\text { Phosphorus in Waters by Flow } \\
\text { Injection Analysis }\end{array}$ & $\begin{array}{l}\text { Lachat QuickChem QC8500 } \\
\text { FIA Automated Ion Analyzer }\end{array}$ \\
\hline $\begin{array}{l}\text { Dissolved } \\
\text { Organic } \\
\text { Carbon }\end{array}$ & DOC & $0.1 \mathrm{ppm}$ & $\begin{array}{l}\text { Determinations of Total } \\
\text { Organic Carbon (TOC), Total } \\
\text { Dissolved Organic Carbon } \\
\text { (DOC) and Dissolved Inorganic } \\
\text { Carbon (DIC) }\end{array}$ & $\begin{array}{l}\text { Shimadzu TOC-5000A } \\
\text { Organic Carbon Analyzer }\end{array}$ \\
\hline
\end{tabular}

Methods and detection limits of water quality parameters sampled in the Saint John River. 


\section{Appendix 3}

\begin{tabular}{|c|c|c|}
\hline \multicolumn{2}{|c|}{ Hypothesis } & Model Structure \\
\hline \multicolumn{3}{|c|}{ Gross Primary Production (GPP) } \\
\hline 1 & $\begin{array}{l}\text { Positive influence of photosynthetically } \\
\text { available radiation (PAR) }\end{array}$ & $=\beta_{1}(\mathrm{PAR})+\beta_{2}(\mathrm{I})$ \\
\hline 2 & $\begin{array}{l}\text { Positive influence of water temperature } \\
\text { (TEMP) }\end{array}$ & $=\beta_{1}(\mathrm{TEMP})+\beta_{2}(\mathrm{I})$ \\
\hline 3 & $\begin{array}{l}\text { Negative influence of water depth change } \\
\text { (DEPTH) }\end{array}$ & $=-\beta_{1}(\mathrm{DEPTH})+\beta_{2}(\mathrm{I})$ \\
\hline 4 & Positive influence of PAR and TEMP & $=\beta_{1}(\mathrm{PAR})+\beta_{2}(\mathrm{TEMP})+\beta_{3}(\mathrm{I})$ \\
\hline 5 & $\begin{array}{l}\text { Positive influence of PAR and TEMP; } \\
\text { negative influence of DEPTH }\end{array}$ & $=\beta_{1}(\mathrm{PAR})+\beta_{2}(\mathrm{TEMP})-\beta_{3}\left(\mathrm{DEPTH}+\beta_{4}(\mathrm{I})\right.$ \\
\hline 6 & $\begin{array}{l}\text { Positive influence of PAR, TEMP and } \\
\text { PAR*water temperature interaction } \\
\text { (PAR*TEMP) }\end{array}$ & $\begin{array}{l}=\beta_{1}(\mathrm{PAR})+\beta_{2}(\mathrm{TEMP})+\beta_{3}(\mathrm{PAR} * \mathrm{TEMP})+ \\
\beta_{4}(\mathrm{I})\end{array}$ \\
\hline 7 & $\begin{array}{l}\text { Positive influence of PAR; negative } \\
\text { influence of DEPTH }\end{array}$ & $=\beta_{1}(\mathrm{PAR})-\beta_{2}(\mathrm{DEPTH})+\beta_{3}(\mathrm{I})$ \\
\hline 8 & $\begin{array}{l}\text { Positive influence of TEMP; Negative } \\
\text { influence of DEPTH }\end{array}$ & $=\beta_{1}(\mathrm{TEMP})-\beta_{2}(\mathrm{DEPTH})+\beta_{3}(\mathrm{I})$ \\
\hline 9 & $\begin{array}{l}\text { Positive influence of PAR, TEMP and } \\
\text { PAR*TEMP; negative influence of DEPTH } \\
\text { (global model) }\end{array}$ & $\begin{array}{l}=\beta_{1}(\mathrm{PAR})+\beta_{2}(\mathrm{TEMP})+\beta_{3}(\mathrm{PAR} * \mathrm{TEMP})+ \\
\beta_{4}(\mathrm{DEPTH})-\beta_{5}(\mathrm{I})\end{array}$ \\
\hline
\end{tabular}

A priori gross primary productivity models for temporal trends in benthic metabolism in the Saint John River, New Brunswick, Canada. Abbreviations used to describe the model structure are listed under each hypothesis with the exception of the ordinate intercept (I). 


\section{Appendix 4}

\begin{tabular}{|c|c|c|}
\hline \multicolumn{2}{|c|}{ Hypothesis } & Model Structure \\
\hline \multicolumn{3}{|c|}{ Community Respiration (CR) } \\
\hline 1 & $\begin{array}{l}\text { Positive influence of gross primary } \\
\text { production (GPP) }\end{array}$ & $=\beta_{1}(\mathrm{GPP})+\beta_{2}(\mathrm{I})$ \\
\hline 2 & $\begin{array}{l}\text { Positive influence of water temperature } \\
\text { (TEMP) }\end{array}$ & $=\beta_{1}(\mathrm{TEMP})+\beta_{2}(\mathrm{I})$ \\
\hline 3 & $\begin{array}{l}\text { Negative influence of water depth change } \\
\text { (DEPTH) }\end{array}$ & $=-\beta_{1}(\mathrm{DEPTH})+\beta_{2}(\mathrm{I})$ \\
\hline 4 & Positive influence of GPP and TEMP & $=\beta_{1}(\mathrm{GPP})+\beta_{2}(\mathrm{TEMP})+\beta_{3}(\mathrm{I})$ \\
\hline 5 & $\begin{array}{l}\text { Positive influence of GPP and TEMP; } \\
\text { negative influence of DEPTH }\end{array}$ & $=\beta_{1}(\mathrm{GPP})+\beta_{2}(\mathrm{TEMP})-\beta_{3}\left(\mathrm{DEPTH}+\beta_{4}(\mathrm{I})\right.$ \\
\hline 6 & $\begin{array}{l}\text { Positive influence of GPP, TEMP and } \\
\text { GPP*water temperature interaction } \\
\text { (GPP*TEMP) }\end{array}$ & $\begin{array}{l}=\beta_{1}(\mathrm{GPP})+\beta_{2}(\mathrm{TEMP})+\beta_{3}(\mathrm{GPP} * \text { TEMP })+ \\
\beta_{4}(\mathrm{I})\end{array}$ \\
\hline 7 & $\begin{array}{l}\text { Positive influence of GPP; negative } \\
\text { influence of DEPTH }\end{array}$ & $=\beta_{1}(\mathrm{GPP})-\beta_{2}(\mathrm{DEPTH})+\beta_{3}(\mathrm{I})$ \\
\hline 8 & $\begin{array}{l}\text { Positive influence of TEMP; Negative } \\
\text { influence of DEPTH }\end{array}$ & $=\beta_{1}(\mathrm{TEMP})-\beta_{2}(\mathrm{DEPTH})+\beta_{3}(\mathrm{I})$ \\
\hline 9 & $\begin{array}{l}\text { Positive influence of GPP, TEMP and } \\
\text { GPP*TEMP; negative influence of DEPTH } \\
\text { (global model) }\end{array}$ & $\begin{array}{l}=\beta_{1}(\mathrm{GPP})+\beta_{2}(\mathrm{TEMP})+\beta_{3}(\mathrm{GPP} * \text { TEMP })+ \\
\beta_{4}(\mathrm{DEPTH})-\beta_{5}(\mathrm{I})\end{array}$ \\
\hline
\end{tabular}

A priori community respiration models for temporal trends in benthic metabolism in the Saint John River, New Brunswick, Canada. Abbreviations used to describe the model structure are listed under each hypothesis with the exception of the ordinate intercept (I). 


\section{Appendix 5}

\begin{tabular}{|c|c|c|}
\hline \multicolumn{2}{|c|}{ Hypothesis } & Model Structure \\
\hline \multicolumn{3}{|c|}{ Net Daily Metabolism (NDM) } \\
\hline 1 & $\begin{array}{l}\text { Positive influence of photosynthetically } \\
\text { available radiation (PAR) }\end{array}$ & $=\beta_{1}(\mathrm{PAR})+\beta_{2}(\mathrm{I})$ \\
\hline 2 & $\begin{array}{l}\text { Positive influence of water temperature } \\
\text { (TEMP) }\end{array}$ & $=\beta_{1}(\mathrm{TEMP})+\beta_{2}(\mathrm{I})$ \\
\hline 3 & $\begin{array}{l}\text { Negative influence of water depth change } \\
\text { (DEPTH) }\end{array}$ & $=-\beta_{1}(\mathrm{DEPTH})+\beta_{2}(\mathrm{I})$ \\
\hline 4 & Positive influence of PAR and TEMP & $=\beta_{1}(\mathrm{PAR})+\beta_{2}(\mathrm{TEMP})+\beta_{3}(\mathrm{I})$ \\
\hline 5 & $\begin{array}{l}\text { Positive influence of PAR and TEMP; } \\
\text { negative influence of DEPTH }\end{array}$ & $=\beta_{1}(\mathrm{PAR})+\beta_{2}(\mathrm{TEMP})-\beta_{3}\left(\mathrm{DEPTH}+\beta_{4}(\mathrm{I})\right.$ \\
\hline 6 & $\begin{array}{l}\text { Positive influence of PAR, TEMP and } \\
\text { PAR*water temperature interaction }^{*} \\
\text { (PAR*TEMP) }\end{array}$ & $\begin{array}{l}=\beta_{1}(\mathrm{PAR})+\beta_{2}(\mathrm{TEMP})+\beta_{3}(\mathrm{PAR} * \mathrm{TEMP})+ \\
\beta_{4}(\mathrm{I})\end{array}$ \\
\hline 7 & $\begin{array}{l}\text { Positive influence of PAR; negative } \\
\text { influence of DEPTH }\end{array}$ & $=\beta_{1}(\mathrm{PAR})-\beta_{2}(\mathrm{DEPTH})+\beta_{3}(\mathrm{I})$ \\
\hline 8 & $\begin{array}{l}\text { Positive influence of TEMP; Negative } \\
\text { influence of DEPTH }\end{array}$ & $=\beta_{1}(\mathrm{TEMP})-\beta_{2}(\mathrm{DEPTH})+\beta_{3}(\mathrm{I})$ \\
\hline 9 & $\begin{array}{l}\text { Positive influence of PAR, TEMP and } \\
\text { PAR*TEMP; negative influence of } \\
\text { DEPTH (global model) }\end{array}$ & $\begin{array}{l}=\beta_{1}(\mathrm{PAR})+\beta_{2}(\mathrm{TEMP})+\beta_{3}(\mathrm{PAR} * \mathrm{TEMP})+ \\
\beta_{4}(\mathrm{DEPTH})-\beta_{5}(\mathrm{I})\end{array}$ \\
\hline
\end{tabular}

A priori net daily metabolism models for temporal trends in benthic metabolism in the Saint John River, New Brunswick, Canada. Abbreviations used to describe the model structure are listed under each hypothesis with the exception of the ordinate intercept (I). 


\section{Curriculum Vitae}

\section{Craig Irwin}

\section{EDUCATION}

MSc Geography Candidate

University of Western Ontario, London, Ontario

Began September 2015

- Research Supervisor: Adam Yates, PhD

- Thesis: "Spatio-temporal variation of benthic metabolism in a large regulated river".

- Research contribution to the Mactaquac Aquatic Ecosystem Study (MAES) focused on biological structure and function of the Saint John River, NB.

BSc Specialization Environmental Science

September 2010 - April 2015

University of Western Ontario, London, Ontario

\section{TEACHING EXPERIENCE}

Teaching Assistant, University of Western Ontario, London, ON

Natural Environment 2131B

January 2016 - April 2016 and January 2017 - April 2017

Instructor: Dr. Sarah Pierce

- Improved student participation in weekly tutorials through integration of creative role-playing exercises

- Participated as a guest lecturer on April 5, 2017 teaching "The Biosphere"

- Provided training in critical reading and facilitated the process of composing academic forms of writing through assignments

Geography of Hazards 2152F

September 2016 - December 2016

Instructor: Mark Moscicki

- Responsible for grading assignments, tests and exams

- Provided thorough feedback on essay assignments

- Met individually with students when they required feedback and assistance on course content and assignments

\section{Weather and Climate 2310A}

September 2015 - December 2015

Instructor: Mark Moscicki

- Lead and supervised weekly laboratory and tutorials

- Prepared and delivered PowerPoint presentations explaining theory behind lab exercises

- Corrected assignments, tests and exams 


\section{PROFESSIONAL EXPERIENCE}

\section{Summer Field Technician, Canadian Rivers Institute, Fredericton, NB} May 2015 - August 2016

- Studied the impact of the Mactaquac Dam on benthic metabolism in the Saint John River

- Used benthic chambers to partition stream habitats for the purpose of measuring productivity and respiration

- Supervised summer students assisting with field work and data collection

- Funded by MAES and graduate NSERC WATER stipend

\section{Research Assistant, Environment Canada, Burlington, ON}

September 2013 - August 2014

- Developed advanced field skills through organizing and participating in multiple water sampling trips

- Collected, processed and analyzed water samples for biomass, dissolved and particulate nutrients

- Responsible for using and calibrating high end lab and field instruments

- Given the opportunity to be in charge of the Lake Winnipeg water quality sampling project 